\title{
The regulation of $\mathrm{mDia} 1$ by autoinhibition and its release by Rho $\bullet$ GTP
}

\section{Michael Lammers, Rolf Rose, Andrea Scrima and Alfred Wittinghofer*}

Department of Structural Biology, Max-Planck-Institute of Molecular Physiology, Dortmund, Germany

Formins induce the nucleation and polymerisation of unbranched actin filaments via the formin-homology domains 1 and 2. Diaphanous-related formins (Drfs) are regulated by a RhoGTPase-binding domain situated in the amino-terminal ( $\mathrm{N}$-terminal) region and a carboxyterminal Diaphanous-autoregulatory domain (DAD), whose interaction stabilises an autoinhibited inactive conformation. Binding of active Rho releases DAD and activates the catalytic activity of mDia. Here, we report on the interaction of DAD with the regulatory $\mathrm{N}$-terminus of mDial $\left(\mathrm{mDia}_{\mathrm{N}}\right)$ and its release by Rho॰GTP. We have defined the elements required for tight binding and solved the three-dimensional structure of a complex between an mDia $_{N}$ construct and DAD by X-ray crystallography. The core DAD region is an $\alpha$-helical peptide, which binds in the most highly conserved region of $\mathrm{mDia}_{\mathrm{N}}$ using mainly hydrophobic interactions. The structure suggests a twostep mechanism for release of autoinhibition whereby Rho॰GTP, although having a partially nonoverlapping binding site, displaces DAD by ionic repulsion and steric clashes. We show that Rho॰GTP accelerates the dissociation of DAD from the mDia $_{\mathrm{N}} \bullet \mathrm{DAD}$ complex.

The EMBO Journal (2005) 24, 4176-4187. doi:10.1038/ sj.emboj.7600879; Published online 17 November 2005 Subject Categories: signal transduction; structural biology Keywords: actin polymerisation; Diaphanous; Diaphanous autoregulatory domain; formin; RhoGTPase

\section{Introduction}

Cellular processes like cell migration, cytokinesis, maintenance of cell polarity, vesicular trafficking, morphology and phagocytosis are driven by the dynamics of the actin cytoskeleton (Pantaloni et al, 2001; Pollard and Borisy, 2003). Actin filaments are polar structures characterised by a fastgrowing barbed and a slow-growing pointed end. They are regulated by extracellular stimuli that activate signalling pathways, including Rho GTP-binding proteins, which in turn, upon activation, can stimulate the actin nucleation and polymerisation machinery (Bishop and Hall, 2000; Pollard and Borisy, 2003; Higgs and Peterson, 2005). So far,

\footnotetext{
*Corresponding author. Department of Structural Biology, Max-Planck Institute of Molecular Physiology, Otto-Hahn-Strasse 11, 44227 Dortmund, Germany. Tel.: +49 231133 2100; Fax: +49 231133 2199; E-mail: alfred.wittinghofer@mpi-dortmund.mpg.de
}

Received: 23 August 2005; accepted: 26 October 2005; published online: 17 November 2005 three conserved mechanisms of actin nucleation-elongation involving WASP/WAVE-Arp2/3, formins and the recently described Drosophila protein Spire have been identified (Pollard and Borisy, 2003; Quinlan et al, 2005).

Formins generate linear, unbranched actin cables and stress fibres (Pruyne et al, 2002; Zigmond, 2004; Higgs, 2005). They are characterised by formin homology (FH) domains, where the $\mathrm{FH} 1$ and $\mathrm{FH} 2$ domains are responsible for the actin nucleation and polymerisation activity (Evangelista et al, 2003; Zigmond et al, 2003). Most formins have additional domains mediating the regulation of the polymerisation activity and are grouped into seven subfamilies: Diaphanous (Dia), dishevelled-associated activator of morphogenesis (DAAM), formin-related gene in leukocytes (FRL), formin-homology domain-containing protein (FHOD), inverted formin (INF), formin (FMN) and delphilin (Higgs, 2005). Some of these contain an FH3 domain, which is the structurally and functionally least conserved $\mathrm{FH}$ domain (Wallar and Alberts, 2003; Zigmond, 2004) and is believed to mediate the subcellular localisation of mDia proteins (Kato et al, 2001; Ozaki-Kuroda et al, 2001).

The central catalytic element of formins is the FH2 domain, which nucleates actin filament formation and regulates filament elongation (Higgs and Peterson, 2005). The FH2 domain is the catalytically active element of formins and is sufficient in vitro for actin nucleation (Pruyne et al, 2002; Li and Higgs, 2003; Shimada et al, 2004; Xu et al, 2004; Higgs and Peterson, 2005). In contrast to tight capping proteins, which do not allow any actin dynamics to occur at their binding site, the FH2 domain forms a leaky cap at the barbed end and allows processive elongation of actin filaments (Wear et al, 2003; Zigmond et al, 2003; Harris et al, 2004; Kovar and Pollard, 2004; Kovar et al, 2005). The structures of a dimeric $\mathrm{FH} 2$ domain construct of the yeast formin Bnilp and a shorter construct of mDial (p140mDia) revealed that the core FH2 domain is all helical (Shimada et al, 2004; Xu et al, 2004). The difference between these structures is a short, unstructured region at the N-terminus, which is of high importance for dimerisation and converts the $\mathrm{FH} 2$ domain from a micromolar inhibitor to a nanomolar inducer of actin polymerisation (Shimada et al, 2004), in line with previous findings on the role of FH2 domains (Pring et al, 2003; Zigmond et al, 2003; Harris et al, 2004; Xu et al, 2004). The structure of the dimeric FH2 domain with TMR-actin shows that each dimer of $\mathrm{FH} 2$ contacts three actin molecules and suggests a mechanism of processive barbed-end elongation in the presence of FH2 (Otomo et al, 2005a).

The proline-rich stretches of the FH1 domain are potential targets for SH3- and WW-domain-containing proteins, but also for profilin (Bedford et al, 1997; Macias et al, 2002; Pring et al, 2003). The actin-profilin complex constitutes the major G-actin pool in the cell and in most cases requires the FH1 domain for efficient polymerisation via the $\mathrm{FH} 2$ domain (Otomo et al, 2005a). Binding of the profilin-actin complex to the FH1 domain mediates fast barbed-end elongation by an 
yet unexplained mechanism that may include high local concentration near the polymerisation site (Zigmond et al, 2003; Romero et al, 2004). It has also been suggested that the increased ATP hydrolysis rate of actin induced by the FH1-FH2 unit decreases the affinity of profilin for actin (Higashida et al, 2004; Romero et al, 2004).

In addition to the FH1 and FH2 domains, Diaphanousrelated formins (Drfs) contain an N-terminally located GTPase-binding domain $\left(\mathrm{mDia}_{\mathrm{N}}\right)$ and a C-terminally located Diaphanous-autoregulatory domain (DAD) (Figure 1A) (Watanabe et al, 1997; Alberts, 2001; Otomo et al, 2005b; Rose et al, 2005b). The Drosophila protein Diaphanous, which plays an important role during cytokinesis (Castrillon and Wasserman, 1994), the Saccharomyces cerevisiae proteins
Bnilp and Bnrlp, and the mammalian homologues of Diaphanous, mDia1-3, belong to this subgroup (Wallar and Alberts, 2003). In the absence of an activating signal, Drfs are in an inactive autoinhibited conformation due to the interaction between the $\mathrm{N}$-terminal regulatory region and DAD (Alberts, 2001; Li and Higgs, 2005; Otomo et al, 2005b; Rose et al, 2005b). Lacking the N-terminal RhoGTPase-binding domain (GBD) and/or the C-terminal DAD mDia1 is constitutively active and induces formation of stress fibres and SRFdependent nuclear transcription (Watanabe et al, 1999; Ishizaki et al, 2001; Copeland and Treisman, 2002; Li and Higgs, 2003). The intrasteric inhibition of Drfs is relieved by binding of active Rho proteins to the regulatory region. Rho proteins are Ras-related GTP-binding proteins, which act as
A

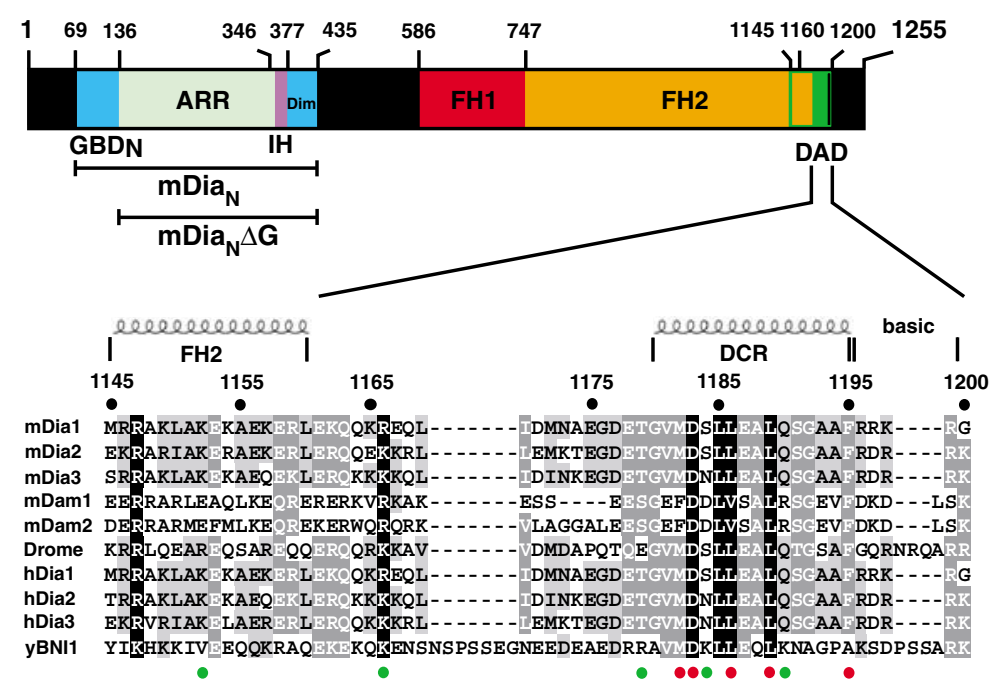

B

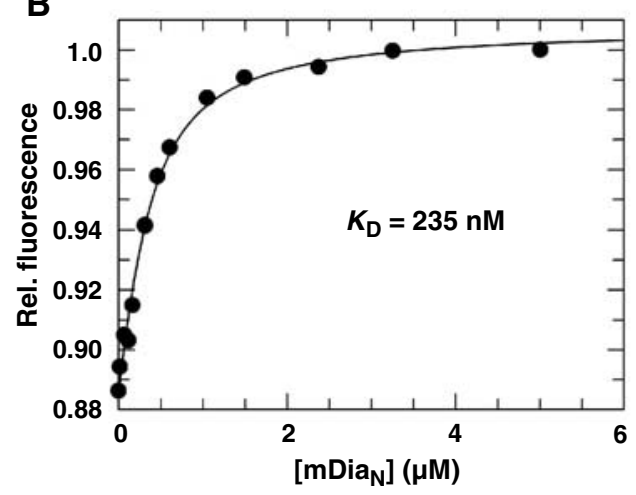

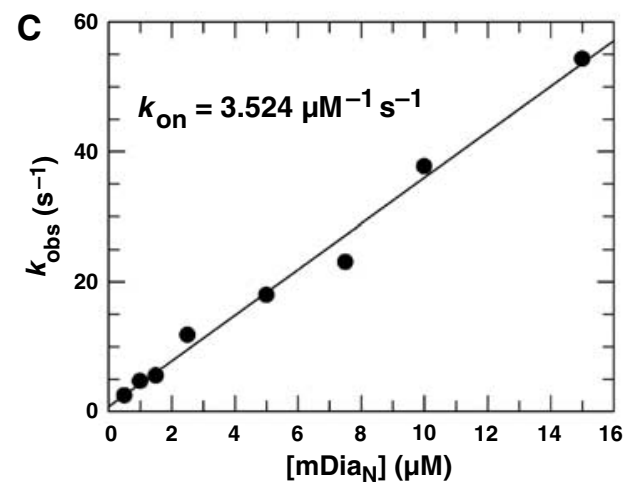

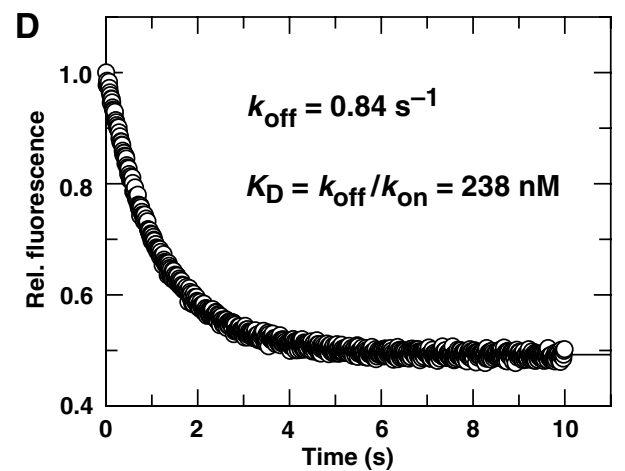

Figure $1 \mathrm{~N}$ - and C-terminal constructs of mDial and their interaction. (A) Schematic representation of the domain structure of mDial and the constructs used. $\mathrm{mDia}_{\mathrm{N}}$, the regulatory region; $\mathrm{GBD}_{\mathrm{N}}$, GTPase-binding domain; $\mathrm{mDia}_{\mathrm{N}} \Delta \mathrm{G}$, the regulatory region minus $\mathrm{GBD}_{\mathrm{N}}$; $\mathrm{ARR}$, armadillorepeat region; IH, interdomain helix; Dim, dimerisation domain; FH1-2, formin-homology domains 1, 2; DAD, Diaphanous-autoregulatory domain. Shown below is an alignment of the $\mathrm{DAD}_{1145-1200}$ fragment from different genes and organisms (accession numbers in brackets): mDia1-3: mouse (O08808; Q9Z207; O70566); mDam1-2: mouse (Q8BPM0; Q80U19); Dia: Drosophila (P48608); hDia1-3, human (O60610; O60879; Q9NSV4); yBNI1, Saccharomyces cerevisiae (P41832). Black shaded residues are conserved in $100 \%$, dark grey shaded in $80 \%$ and bright grey shaded in $60 \%$ of the depicted organisms at the specific position. Furthermore, residues with similar physiochemical properties are combined into groups. Residues 1145-1160 might belong to the FH2 domain and have a helical structure as shown previously (Shimada et al, 2004); the structure of the DCR (residues 1180-1195) was determined here. The red and green circles below the alignment represent residues whose mutations do or do not influence affinity towards $\mathrm{mDia}_{\mathrm{N}}$, respectively. (B) Determination of affinity between F-DAD $\mathrm{D}_{1145-1200}$ and $\mathrm{mDia}_{\mathrm{N}}$ using fluorescence. F-DAD ${ }_{1145-1200}(100 \mathrm{nM})$ was titrated with increasing concentration of $\mathrm{mDia}_{\mathrm{N}}$ and the change in fluorescence obtained is plotted against the concentration of $\mathrm{mDia}_{\mathrm{N}}$. The data were fitted to a quadratic binding equation. (C) Association kinetics of $\mathrm{F}-\mathrm{DAD} \mathrm{D}_{1145-1200}$ and $\mathrm{mDia}_{\mathrm{N}}$ as determined by stopped flow. F-DAD is reacted with increasing concentrations of $\mathrm{mDia}_{\mathrm{N}}$ and the observed first-order rate constants $\left(k_{\text {obs }}\right)$ are plotted against the $\mathrm{mDia}_{\mathrm{N}}$ concentration. The slope of the linear fit represents $k_{\text {on }}$. (D) The dissociation rate constant $k_{\text {off }}$ is determined by incubating $100 \mathrm{nM}$ of a preformed F-DAD $\bullet \mathrm{mDia}_{\mathrm{N}}$ complex in the presence of a large excess of unlabelled DAD peptide. The fluorescence transient is fitted to a single-exponential decay. 
molecular switches that cycle between an inactive GDP- and an active GTP-bound conformation. In the latter state, they interact with downstream effectors defined as proteins, which bind tightly to the GTP-bound conformation only (Vetter and Wittinghofer, 2001; Etienne-Manneville and Hall, 2002). A common mechanism by which Rho proteins activate effectors is the release of an intramolecular inhibitory interaction, which can be found in many effector proteins such as WASP and the Ser/Thr kinases PAK, ROK and PKN (Maesaki et al, 1999; Millard et al, 2004). In the case of PAK, upon binding of active Rac or Cdc42, an intramolecular regulatory domain is displaced from the active site and thus allows substrate binding (Lei et al, 2000, 2005). For WASP, it is the interaction of the N-terminal CRIB domain with parts of the C-terminal VCA motif that is relieved by Cdc42 (Buck et al, 2004; Leung and Rosen, 2005). In vitro, the interaction of the regulatory $\mathrm{N}$-terminus $\left(\mathrm{mDia}_{\mathrm{N}}\right)$ with $\mathrm{DAD}$ of mDia1 is released by active Rho, thus mimicking the formin activation reaction (Li and Higgs, 2005; Rose et al, 2005b), although some studies suggest that Rho•GTP may not be quite sufficient for full relief of autoinhibition (Li and Higgs, 2003, 2005).

Recently, the structures of $\mathrm{mDia}_{\mathrm{N}}$ (residues 69-451) alone and in complex with RhoC•GppNHp were solved by X-ray crystallography (Otomo et al 2005b; Rose et al, 2005b), revealing that the all-helical $\mathrm{mDia}_{\mathrm{N}}$ consists of the three subdomains: $\mathrm{GBD}_{\mathrm{N}}$ (the N-terminal part of the Rho-binding domain), the armadillo-repeat region (ARR) and a C-terminal dimerisation domain (Dim). Surprisingly, mutational and NMR studies showed that the DAD and Rho•GTP binding sites on the $\mathrm{mDia}_{\mathrm{N}}$ surface were apparently not overlapping, suggesting that the mutual exclusive binding of Rho and DAD is not simply due to steric exclusion (Otomo et al, 2005b; Rose et al, 2005b). In order to more clearly identify the DAD binding site and to clarify the structural basis for regulation of the Drf subfamily of proteins, we solved the three-dimensional structure of the complex between $\mathrm{mDia}_{\mathrm{N}} \Delta \mathrm{G}$ (residues 136-451) and DAD encompassing residues 1145-1200. Using a number of biochemical and biophysical measurements, we can propose a two-step binding mechanism for the release of autoinhibition by Rho•GTP.

\section{Results}

\section{The mDia $_{N}$ binds DAD with submicromolar affinity}

The N-terminal regulatory domain of mDial, $\mathrm{mDia}_{\mathrm{N}}$, binds Rho•GTP and the C-terminal DAD in a mutually exclusive manner, where Rho•GTP binds with a low nanomolar affinity to $\mathrm{mDia}_{\mathrm{N}}$ (Rose et al, 2005b). In order to compare Rho with DAD binding towards $\mathrm{mDia}_{\mathrm{N}}$, we determined the kinetic and equilibrium constants of DAD binding using isothermal titration calorimetry (ITC) and fluorescence-based equilibrium and kinetic measurements. For these, a fluorescently labelled DAD fragment (F-DAD) was made by coupling 1,5Iaedans to an extra cysteine on the C-terminus of the DAD fragment encompassing residues $1145-1200\left(\mathrm{DAD}_{1145-1200}\right)$ (Figure 1A). Binding of the fluorescent F-DAD to $\mathrm{mDia}_{\mathrm{N}}$ leads to an increase in fluorescence, presumably due to transfer of the fluorescence label to a more hydrophobic environment. This fluorescence change was used for equilibrium binding measurements, by titrating F-DAD with increasing concentrations of $\mathrm{mDia}_{\mathrm{N}}$ to obtain a $K_{\mathrm{D}}$ of $235 \mathrm{nM}$ (Fig 1B).
Furthermore, active site titration using concentrations of reactants above the $K_{\mathrm{D}}(3 \mu \mathrm{M}$; roughly 13 -fold above the $K_{\mathrm{D}}$ ) shows that DAD binds with a clear 1:1 stoichiometry (data not shown).

To analyse the dynamics of the reaction, we measured the association and dissociation rate constants $k_{\text {on }}$ and $k_{\text {off }}$ by stopped-flow. For association, F-DAD was mixed with increasing concentrations of $\mathrm{mDia}_{\mathrm{N}}$, and the observed rate constants $k_{\text {obs }}$ were plotted against the $\mathrm{mDia}_{\mathrm{N}}$ concentration. This plot was linear over the concentration range and gives, from the slope, an association rate constant $k_{\text {on }}$ of $3.5 \mu \mathrm{M}^{-1} \mathrm{~s}^{-1}$ (Figure 1C). The dissociation rate constant was obtained by following the fluorescence decrease on incubating the preformed $\mathrm{F}-\mathrm{DAD} \bullet \mathrm{mDia}_{\mathrm{N}}$ complex with an excess of unlabelled $\mathrm{DAD}_{1145-1200}$ to obtain a $k_{\text {off }}$ of $0.84 \mathrm{~s}^{-1}$ (Figure 1D). The resulting dissociation equilibrium constant $K_{\mathrm{D}}\left(k_{\text {off }} / k_{\text {on }}\right)$ is $238 \mathrm{nM}$, in good agreement with the equilibrium titration experiment (Figure 1C).

For an independent measurement of affinity and to get more information on the thermodynamics of binding, we measured the interaction of DAD with mDia $_{N}$ via ITC, which gives an equilibrium dissociation constant $\left(K_{\mathrm{D}}\right)$ of $109 \mathrm{nM}$ and a stoichiometry of $1: 1$ (Figure $2 \mathrm{~A}$ and Table I). The affinity is twofold higher than determined by fluorescence, which is due to the fluorescence label at the C-terminus of DAD, since an ITC experiment using $\mathrm{mDia}_{\mathrm{N}}$ and F-DAD resulted in an affinity of $249 \mathrm{nM}$ (data not shown). Quite unusually for a protein-protein interaction, the $\mathrm{mDia}_{\mathrm{N}^{-}}$ $\mathrm{DAD}_{1145-1200}$ interaction is highly endothermic, with an enthalpy change $\Delta H$ of $10.2 \mathrm{kcal} \mathrm{mol}^{-1}$. The thermodynamically unfavourable enthalpy of the reaction is compensated by the highly favourable (positive) entropic contribution ( $T \Delta S=19.5 \mathrm{kcal} \mathrm{mol}^{-1}$ ), which is the driving force of the reaction.

\section{The core DAD binding site on DDia $_{N}$}

The N-terminal part of the Rho binding site $\left(\mathrm{GBD}_{\mathrm{N}}\right)$ is detached from the rest of the ARR of $\mathrm{mDia}_{\mathrm{N}}$ (see Figure 2 in Rose et al, 2005b). We thus wondered about the contribution of this fragment to DAD binding, expressed $\mathrm{mDia}_{\mathrm{N}} \Delta \mathrm{G}$, and measured its interaction with $\mathrm{DAD}_{1145-1200}$. It binds with an affinity of $110 \mathrm{nM}$ (stoichiometry 1:1), very similar to $\mathrm{mDia}_{\mathrm{N}}$, and the enthalpy is likewise unfavourable, with $\Delta H \quad 7.4 \mathrm{kcalmol}^{-1}$ and a compensating entropy term of $16.8 \mathrm{kcal} \mathrm{mol}^{-1}$ (Figure 2B). Thus, the three-helix motif $\mathrm{GBD}_{\mathrm{N}}$ makes no apparent contribution to the binding of $\mathrm{DAD}$ and $\mathrm{mDia}_{N} \Delta \mathrm{G}$ is thus well suited for structural studies on the DAD-mDia ${ }_{\mathrm{N}}$ interaction (see below).

In contrast to $\mathrm{mDia}_{N}, \mathrm{DAD}$ binding to $\mathrm{mDia}_{N} \Delta \mathrm{G}$ is not released by RhoA, as shown by a fluorescence polarisation assay. Here, $0.5 \mu \mathrm{M}$ of a DAD peptide encompassing residues 1175-1196 labelled at the N-terminus with a fluorescent AMCA label (from now: A-DAD) was treated with $2 \mu \mathrm{M}$ of either $\mathrm{mDia}_{\mathrm{N}}$ or $\mathrm{mDia}_{\mathrm{N}} \Delta \mathrm{G}$ and the development of polarisation was followed. Due to complex formation and the corresponding increase of mass, the mobility of the fluorophore decreases, which leads to an increase in the polarisation signal (Figure 3). When adding $4 \mu \mathrm{M}$ of active RhoA $\bullet$ GppNHp to the fluorescent A-DAD-mDia ${ }_{N}$ complex, polarisation returns to the starting level, whereas addition of RhoA GDP does not lead to dissociation of the complex, as shown previously under slightly different conditions (Rose 
A

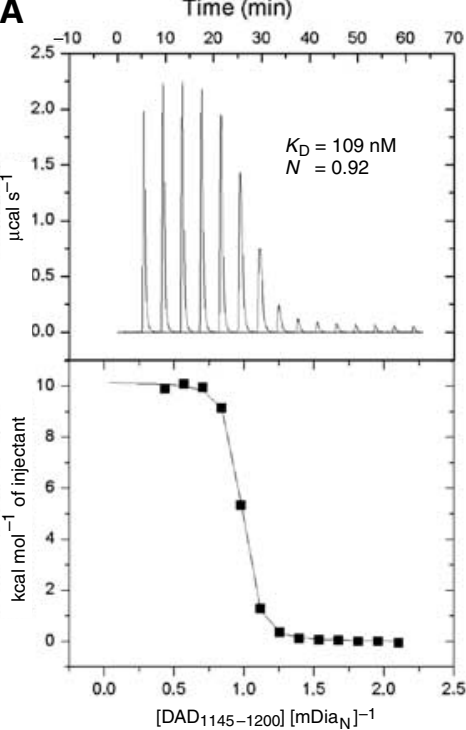

B Time (min)

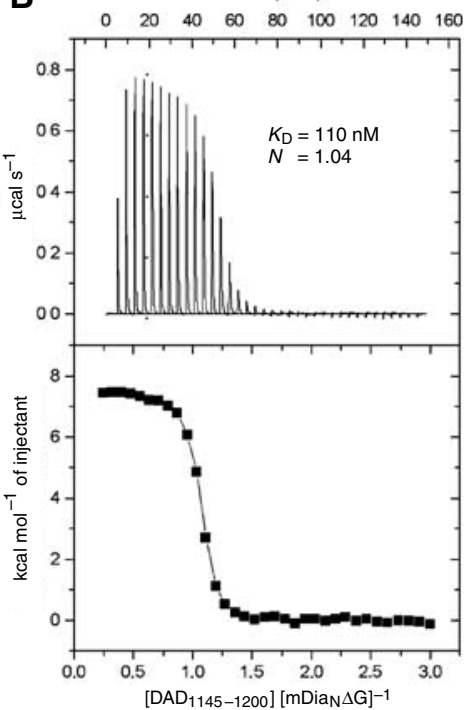

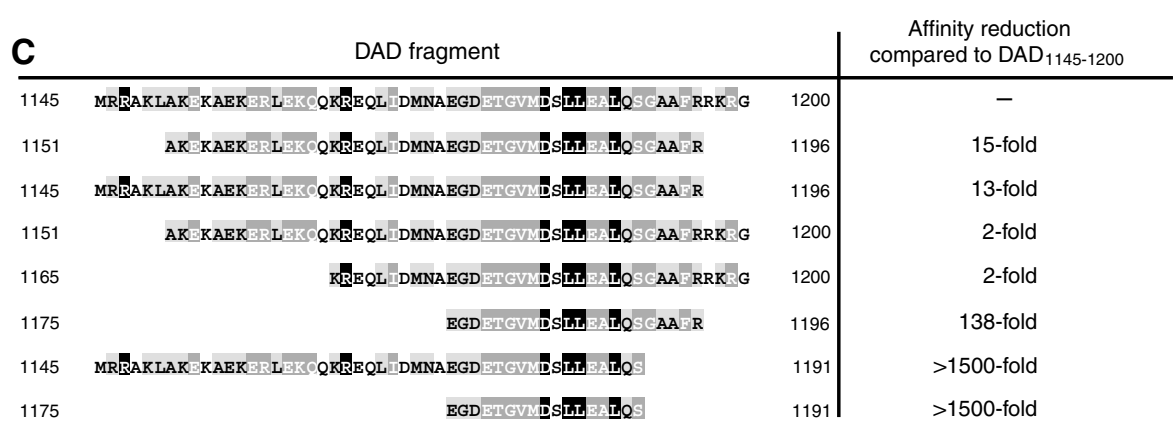

Figure 2 ITC analysis of the DAD-mDia ${\text { interaction. ITC of the interaction between } \mathrm{DAD}_{1145-1200} \text { and either } \mathrm{mDia}}_{N}(\mathbf{A})$ or $\mathrm{mDia}{ }_{N} \Delta \mathrm{G}(\mathbf{B})$, measured by titrating $40 \mu \mathrm{M} / 30 \mu \mathrm{M} \mathrm{mDia}_{N} / \mathrm{mDia}_{N} \Delta \mathrm{G}$ in the chamber with $940 \mu \mathrm{M} / 400 \mu \mathrm{M} \mathrm{DAD}_{1145-1200}$ in the syringe. Top panels, raw heating power over time; bottom panels, fit of the integrated energy values normalised for injected protein. (C) Result of affinity analysis of different DAD fragments for $\mathrm{mDia}_{\mathrm{N}}$, measured by ITC as in (A, B) and indicated as affinity reduction relative to the 'full-length' $\mathrm{DAD} \mathrm{D}_{1145-1200}$ fragment.

et al, 2005b). However, with the A-DAD $\bullet \mathrm{mDia}_{\mathrm{N}} \Delta \mathrm{G}$ complex, neither the active nor the inactive Rho can release DAD from the complex, even after addition of a 100-fold excess (data not shown). Using this polarisation assay, the same results could be obtained using the longer F-DAD fragment, which includes the basic residues in the patch 1197-RKRG-1200, which also demonstrates that the nature of the fluorescence label does not influence the results (Supplementary Figure 1). Thus, although part of the Rho binding site is on the ARR region, as shown by the structure of the $\mathrm{mDia}_{\mathrm{N}} \bullet$ RhoC complex, the affinity of Rho GTP for this region is too weak to effectively release $\mathrm{DAD}$, or the mode of binding is inappropriate for such a release.

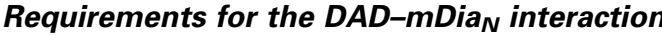

The DAD regions of Drfs can be aligned and show different levels of conservation (Figure 1A), with a central portion that is conserved between Bnilp and mammalian Dia. In UniProt (www.uniprot.org), it is defined as a stretch of 15 amino acids (mDia1: aa 1180-1194) with a large number of identical and conserved residues. In order to sort out the requirements for efficient intramolecular interaction, we screened various DAD constructs and mutants for interaction with $\mathrm{mDia}_{\mathrm{N}}$. Whereas the 17 mer DAD $_{1175-1191}$ was synthesised with and the 22mer $\mathrm{DAD}_{1175-1196}$ peptide with and without a fluorescent label, all the other DAD fragments were recombinantly expressed as GST fusion proteins and cleaved. Using ITC, values for affinity, stoichiometry, enthalpy and entropy of the binding were obtained and are summarised in Table I and Figure 2C. The 22mer containing the highly conserved 15 amino acids of DAD (Figure 1A) has micromolar affinity and is essential for binding. $\mathrm{N}$ - and $\mathrm{C}$-terminal elongations of this DAD core lead to an increasing affinity towards $\mathrm{mDia}_{\mathrm{N}}$. The 56mer peptide covering the complete $\mathrm{DAD}$ region shows a 138-fold increase in affinity, with the C-terminus having a much larger influence. Comparison of $\mathrm{DAD}_{1151-1200}$ $\left(K_{\mathrm{D}}=209 \mathrm{nM}\right)$, DAD ${ }_{1165-1200}\left(K_{\mathrm{D}}=194 \mathrm{nM}\right)$ and $\mathrm{DAD}_{1145-1196}$ $\left(K_{\mathrm{D}}=1.4 \mu \mathrm{M}\right)$ with the fragments $\mathrm{DAD}_{1151-1196}\left(K_{\mathrm{D}}=1.6 \mu \mathrm{M}\right)$ and $\mathrm{DAD}_{1145-1200}\left(K_{\mathrm{D}}=109 \mathrm{nM}\right)$ demonstrates that the C-terminal residues 1197-RKRG-1200 are mostly responsible for the increased affinities, while the N-terminal residues 1145-1165 have nearly no effect. This is consistent with the findings of Li and Higgs (2005), who found that a 1177-1200 DAD peptide shows a $250 \mathrm{nM}$ affinity towards mDial 1-548 and 129-548. The synthesised DAD 17mer fragment 11751191 and the recombinantly expressed $\mathrm{DAD}_{1145-1191} 47 \mathrm{mer}$ fragment do not show measurable binding affinity in ITC. Even in a qualitative polarisation assay using an AMCA- 
Table I Thermodynamic properties of binding of $\mathrm{mDia}_{\mathrm{N}}$ to $\mathrm{DAD}_{1145-1200}$, as determined by ITC

\begin{tabular}{lcccc}
\hline Mutation & $K_{\mathrm{D}}(\mathrm{nM})$ & $\begin{array}{c}\Delta H \\
\left(\mathrm{kcal} \mathrm{mol}^{-1}\right)\end{array}$ & $\begin{array}{c}T \Delta S \\
\left(\mathrm{kcal} \mathrm{mol}^{-1}\right)\end{array}$ & $N$ \\
\hline WT & $109 \pm 10$ & $10.16 \pm 0.05$ & 19.5 & 0.9 \\
N165D & $130 \pm 6$ & $10.17 \pm 0.03$ & 19.4 & 1.0 \\
N217A & $8470 \pm 697$ & $8.01 \pm 0.28$ & 14.8 & 1.0 \\
A256D & $\geqslant 1440000^{\mathrm{a}}$ & & & \\
I259D & $\geqslant 232000^{\mathrm{a}}$ & & & \\
E264K & $91 \pm 9$ & $10.16 \pm 0.05$ & 17.9 & 1.1 \\
D366A & $153 \pm 6$ & $7.81 \pm 0.02$ & 16.9 & 1.0 \\
R269E & $90 \pm 5$ & $9.5 \pm 0.03$ & 18.9 & 1.1 \\
K1152A & $117 \pm 7$ & $8.69 \pm 0.03$ & 18.0 & 1.1 \\
R1166A & $288 \pm 13$ & $7.92 \pm 0.03$ & 16.7 & 0.9 \\
T1179A & $180 \pm 8$ & $9.51 \pm 0.04$ & 18.6 & 0.9 \\
T1179D & $500 \pm 19$ & $9.85 \pm 0.05$ & 18.3 & 1.1 \\
M1182A & $88500 \pm 3370$ & $17.92 \pm 1.22$ & 23.3 & 1.0 \\
M1182D & $\geqslant 200000^{\mathrm{a}}$ & & & \\
D1183R & $4100 \pm 81$ & $9.03 \pm 0.04$ & 16.3 & 1.5 \\
D1183N & $934 \pm 24$ & $12.09 \pm 0.49$ & 20.2 & 1.0 \\
S1184D & $216 \pm 17$ & $6.77 \pm 0.06$ & 15.7 & 0.9 \\
L1186A & $1830 \pm 91$ & $8.10 \pm 0.08$ & 15.8 & 1.0 \\
L1189A & $9804 \pm 865$ & $9.06 \pm 0.52$ & 15.8 & 1.1 \\
Q1190A & $114 \pm 7$ & $8.19 \pm 0.04$ & 17.5 & 1.2 \\
F1195A & $\geqslant 150000^{\mathrm{a}}$ & & & \\
& & & & \\
mDia & & & & \\
DAD & $110 \pm 7$ & $7.43 \pm 0.03$ & 16.8 & 1.0 \\
\hline WT & & & & \\
\hline
\end{tabular}

$N$ is the stoichiometry of binding. The last row shows the characteristics concerning the $\mathrm{mDia}_{\mathrm{N}} \Delta \mathrm{G}-\mathrm{DAD}_{1145-1200 \mathrm{WT}}$ interaction. ${ }^{a}$ Affinity of A256D, I259D, F1195A and M1182D is too low for accurate measurements of enthalpy, entropy and stoichiometry.

labelled $\mathrm{DAD}_{1175-1191}$ peptide and F-DAD ${ }_{1145-1191}$, no increase of polarisation could be detected upon addition of $\mathrm{mDia}_{\mathrm{N}}$, even in a high excess, showing that some of the residues between 1192 and 1200 are essential for binding to $\mathrm{mDia}_{\mathrm{N}}$ (data not shown).

\section{Structure of the $\mathrm{mDia}_{N} \Delta G-D A D_{1145-1200}$ complex}

The $\operatorname{mDia}_{\mathrm{N}} \Delta \mathrm{G} \bullet \mathrm{DAD}_{1145-1200}$ complex was purified using a bicistronic expression system in Escherichia coli. The soluble complex could be purified using a GSH-Sepharose column, subsequent cleavage and size exclusion chromatography (S200 16/60). It eluted with an apparent molecular mass of about $80 \mathrm{kDa}$ (data not shown), corresponding to a $2: 2$ hetero-tetramer, which was crystallised. While no molecular replacement solution could be found for a native data set, the better diffracting Se-Met crystals and the structure of mDia $_{\mathrm{N}}$ in complex with RhoC $\bullet$ GppNHp (Table II; Rose et al, 2005a, b; PDB 1Z2C) were used for phasing by molecular replacement. The anomalous signal of Se-Met1182 was used to identify DAD. A ribbon model of the complete structure shows that the DAD binding site is located on the concave site of the ARR (Figure 4A), as predicted from previous experiments (see Figure 3; Rose et al, 2005b; see also Otomo et al, 2005b). As the site chain density of the DAD peptide corresponding to chain $\mathrm{D}$ of the hetero-tetramer was better defined, chain $\mathrm{B}\left(\mathrm{mDia}_{\mathrm{N}} \Delta \mathrm{G}\right)$ and chain $\mathrm{D}$ (DAD) will be used for further discussions (Table III).

The overall structure of $\mathrm{mDia}_{N} \Delta \mathrm{G}$ shows no significant conformational changes for the ARR in comparison to both the structure of $\mathrm{mDia}_{\mathrm{N}}$ in complex with RhoC•GppNHp and one subunit of the unliganded form of the protein (Figure $4 \mathrm{~B}$ and Table IV) (Otomo et al, 2005b; Rose et al, 2005b). The long interdomain helix and the dimerisation domain appear to be more flexible and show the largest differences. In the structure of the unbound form (Otomo et al, 2005b), the long interdomain helix of one of the monomers is interrupted and causes a large distortion of the dimerisation domain, which cannot be observed in the two other structures and the other monomer of the unbound structure (Figure 4B), suggesting that the deviation is due to the extensive crystal contacts at the N-terminus.

Only 16 (1180-1195) of the 56 residues of the DAD fragment used for crystallisation are visible in the structure (Figure 4C, Supplementary Figure 2). The first 12 of these form an amphipathic helix that makes extensive hydrophobic contacts to the second helices of armadillo-repeats (ARM) two, three and four. At residue 1192, the polypeptide makes a $90^{\circ}$ bend and seems to form another helical turn (Figure 4A and C). Apart from the hydrophobic interactions, Asp1183 forms a salt bridge with Lys213 of ARM2 (Figure 4C). The same aspartate is also in contact distance of Asn217 (Table I), which is important for the correct orientation of the 'arginine wedge' (Arg68) of Rho, being crucial for the binding of the latter (Rose et al, 2005b). Although the precise orientation of the motif SGAA directly C-terminal of the core DAD was difficult to trace at this resolution, Phe1195 following the SGAA motif is clearly defined. It is wedged into the space between the interdomain helix and ARM4 (Figure 4C).

In the structure, DAD is situated on a patch of surface exposed residues with very high conservation between different Drfs down to Entamoeba histolytica (Figure 4D). It is close to, but only marginally overlapping with the Rho binding site (see below), as had been predicted from NMR and biochemical data (Otomo et al, 2005b; Rose et al, 2005b). We have shown above that the basic residues (1196-RRKRG1200) following the 1191-SGAAF-1195 motif are essential for high-affinity binding (Figure $2 \mathrm{C}$ and Table I), but are not visible in the structure of the complex, most likely due to the high salt conditions used in crystallisation, which tend to mask ionic interactions in the crystal. We wondered where this basic stretch of residues could bind and can identify two negatively charged grooves on the interdomain helix or between ARM3 and ARM4, with conserved residues as the possible binding sites (Figure 4D and E). However, since mutation of Asp366 to Ala did not lead to a significant decrease of affinity towards $\mathrm{DAD}$, we are uncertain about the path of the DAD polypeptide on $\mathrm{mDia}_{\mathrm{N}}$ (Table I).

The topology of the complex presented here is in analogy to the interactions of catenin with the competing ligands Tcf, cadherin and APC (Graham et al, 2000; Eklof Spink et al, 2001), and to the binding of Ran to the concave side of the helical HEAT repeat motif of its effector $\beta$-importin (Chook and Blobel, 1999; Vetter et al 1999), suggesting that the concave side of armadillo or HEAT repeats is a favoured protein-protein interaction surface.

\section{Mutational analysis of the interface}

To analyse the interface in more detail, we introduced point mutations into either $\mathrm{DAD}$ or $\mathrm{mDia}_{\mathrm{N}}$ and measured the affinities using ITC. The hydrophobic residues Phe1195 and Met1182 make major contributions to affinity as their substitution by Ala leads to roughly 800 - and 1400 -fold reductions in affinity, respectively (Table I). As a control, the mutants T1179A, S1184A and Q1190A with substitutions of 

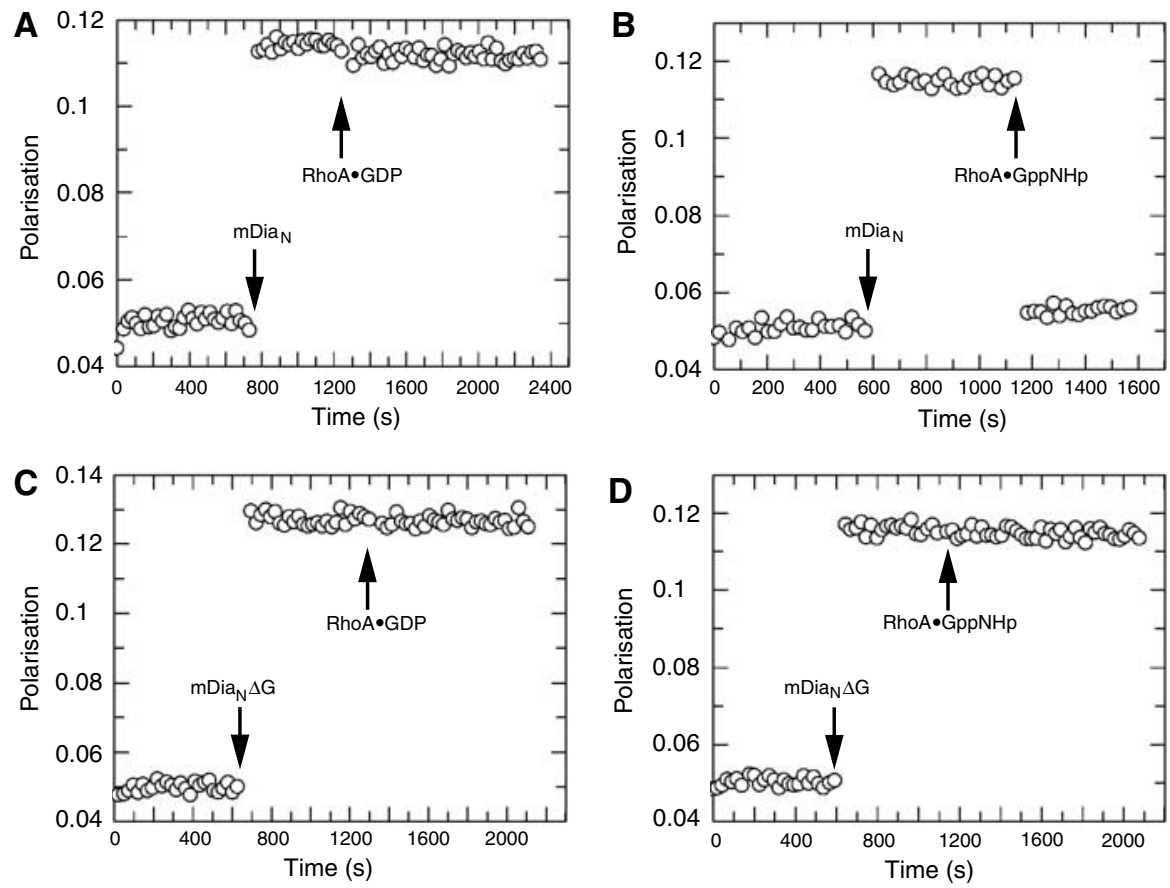

Figure 3 Fluorescence polarisation assay to analyse competitive binding of RhoA or DAD towards $\mathrm{mDia}_{\mathrm{N}}$ and $\mathrm{mDia}{ }_{\mathrm{N}} \Delta \mathrm{G}$, respectively. Fluorescently (AMCA)-labelled A-DAD peptide (residues 1175-1196) is incubated with either $\mathrm{mDia}_{\mathrm{N}}(\mathbf{A}, \mathbf{B})$ or mDia ${ }_{N} \Delta \mathrm{G}(\mathbf{C}, \mathbf{D})$ and leads to increase of the polarisation signal due to the decreased mobility of A-DAD upon complex formation. RhoA $\bullet$ GppNHp (B, D) and RhoA $\bullet$ GDP $(\mathrm{A}, \mathrm{C})$ are added as indicated.

Table II Data collection statistics

\begin{tabular}{ll}
\hline Wavelength $(\AA)$ & 0.950 \\
Resolution $(\AA)$ & 3.4 \\
Space group & $P 6122$ \\
Unit-cell parameters & $a=138.7, b=138.7, c=210.9$ \\
VM $\left(\AA^{3} \mathrm{Da}^{-1}\right)$ & 3.6 \\
Total measurements & 437327 \\
Unique reflections & 33924 \\
Average redundancy & 11.51 \\
$I / \sigma(I)$ & $21.24(6.92)$ \\
Completeness $(\%)$ & $99.4(99.4)$ \\
Wilson $B$-factor $\left(\AA^{2}\right)$ & 77 \\
$R_{\text {sym }}(\%)$ & 8.4 \\
\hline
\end{tabular}

residues on the hydrophilic side of the helix have only a minor effect on affinity. The disruption of the salt bridge between Asp1183 and Lys213 led to a 37-fold reduction in affinity, further supporting the notion that hydrophobic interactions provide the major driving force of the interaction between $\mathrm{mDia}_{\mathrm{N}}$ and DAD (Table I).

Recently, it was shown structurally and in mutational studies that although Rho GTP and DAD binding to $\mathrm{mDia}_{\mathrm{N}}$ are mutually exclusive, their binding sites do not seem to overlap (Otomo et al, 2005b; Rose et al, 2005b). It was shown that the mutations $\mathrm{A} 256 \mathrm{D}$ and $\mathrm{I259D}$ in mDia $_{\mathrm{N}}$ affected $\mathrm{DAD}_{1145-1200}$ binding but not RhoA binding, and the mutation N165D affected RhoA binding but not DAD $_{1145-1200}$ binding (Figure 4D) (Otomo et al, 2005b; Rose et al, 2005b). The affinities of these and additional mDia $_{N}$ mutants towards $\mathrm{DAD}_{1145-1200}$ were further characterised by ITC measurements. A256D and I259D were drastically reduced indeed to approximately $1.4 \mathrm{mM}$ and $232 \mu \mathrm{M}$, respectively, as compared to $109 \mathrm{nM}$ for wild type (Table I). In contrast, mutant N165D, which does affect Rho binding (Rose et al, 2005b), showed wild-type affinity towards $\mathrm{DAD}_{1145-1200}$, with a value $130 \mathrm{nM}$. While the mutant N217A $\left(K_{\mathrm{D}}=8.4 \mu \mathrm{M}\right)$ does influence DAD binding, mutations of residues far away from the Rho binding site, such as R269E, E264K and D366A, do not $\left(K_{\mathrm{D}}=91,90\right.$ and $153 \mathrm{nM}$ ) (Table I).

\section{Rho actively displaces DAD from $\mathrm{mDia}_{N}$}

After localising the DAD binding site by both biochemical and structural analysis, we wondered how Rho•GTP would dissociate the $\mathrm{mDia}_{\mathrm{N}} \bullet \mathrm{DAD}_{1145-1200}$ complex, which is a mimic of the autoinhibited full-length mDia1. We and others have shown that Rho•GTP can displace DAD from binding (Figure 3) (Li and Higgs, 2003; Rose et al, 2005b), which is supported by our affinity measurements, that show a 18 -fold higher affinity of $\mathrm{mDia}_{\mathrm{N}}$ for Rho $\left(K_{\mathrm{D}}=6 \mathrm{nM}\right)$ (Rose et al, $2005 \mathrm{~b})$ compared to $\mathrm{DAD}_{1145-1200}-\mathrm{mDia}_{\mathrm{N}}\left(K_{\mathrm{D}}=109 \mathrm{nM}\right)$. Considering the only slightly overlapping binding sites (see below), the question arises as to why and how Rho•GTP would displace DAD. Does Rho passively compete with DAD for a marginal overlapping binding site on $\mathrm{mDia}_{\mathrm{N}}$ and only binds after DAD has dissociated, or does it actively induce DAD dissociation? If the former holds, Rho GTP binding would be regulated by the kinetics of $\mathrm{mDia}_{\mathrm{N}}-\mathrm{DAD}$ dissociation, which is $0.84 \mathrm{~s}^{-1}$ for the intermolecular interaction investigated here (Figure 1D), but would be expected to be much slower for the intramolecular interaction of full-length mDia.

Since the structure of the ARR is very similar between the $\mathrm{mDia}_{\mathrm{N}} \Delta \mathrm{G} \bullet \mathrm{DAD}_{1145-1200}$ and the $\mathrm{mDia}_{\mathrm{N}} \bullet \mathrm{RhoC} \bullet \mathrm{GppNHp}$ structure (Figure 4B), we can use the superimpositon of the two structures to show that the Rho and the core DAD binding sites are very close to each other, but overlap only 

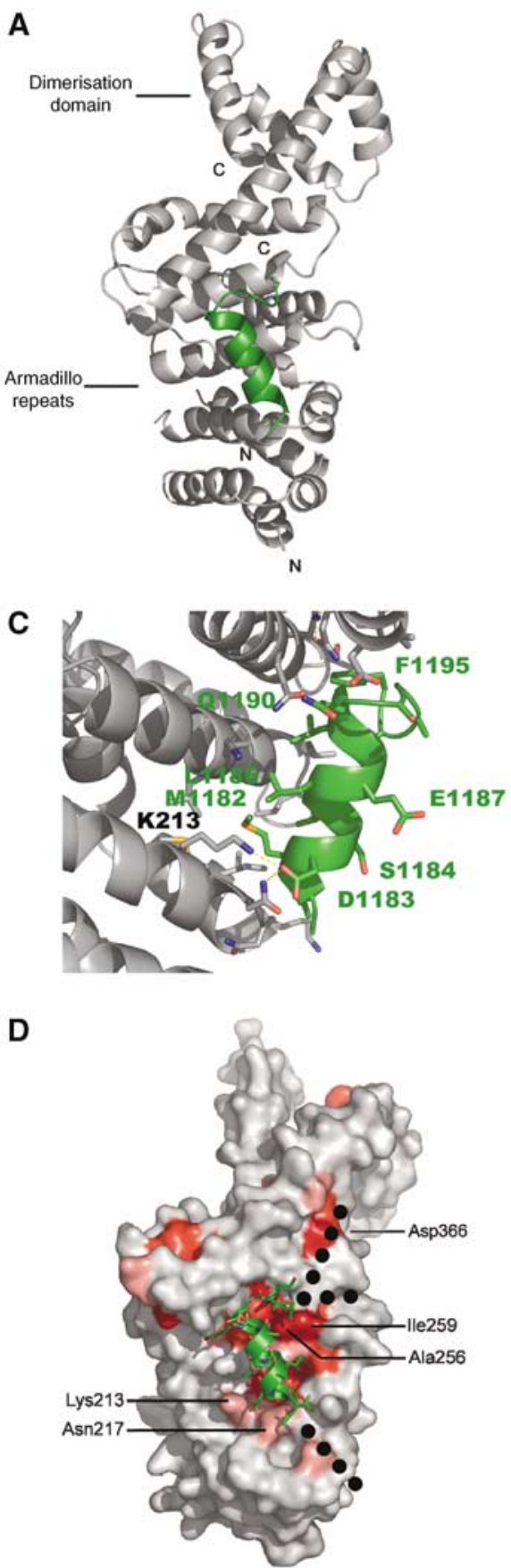
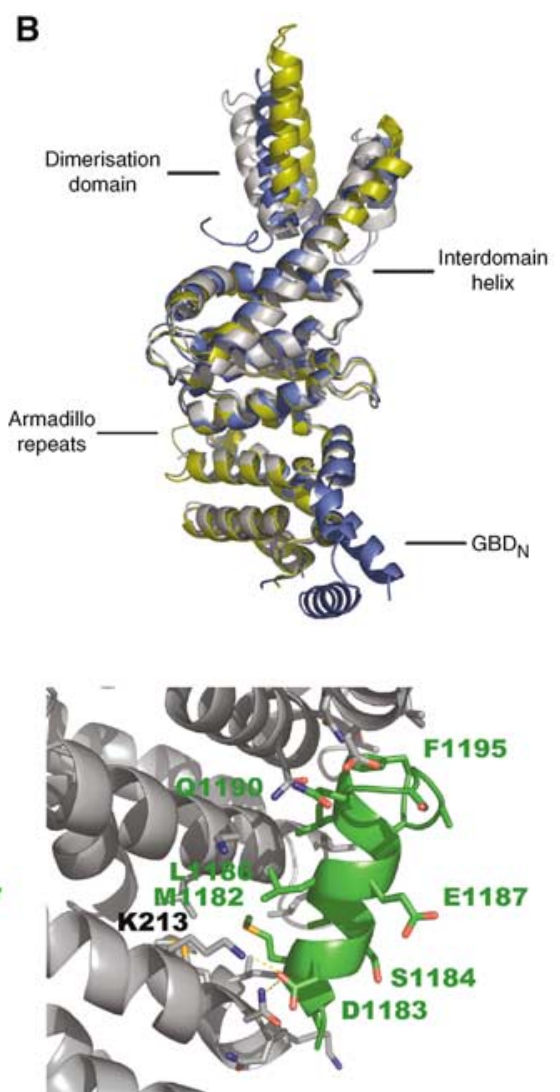

E

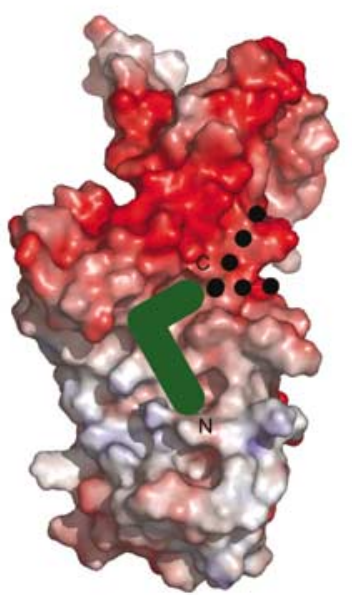

Figure 4 Structure of the $\mathrm{mDia}_{\mathrm{N}} \Delta \mathrm{G}$-DAD complex. (A) Ribbon diagram of the structure, where $m D i a_{N} \Delta \mathrm{G}$ is grey and DAD green. Only residues $1180-1195$, the DCR, are visible in the structure. (B) Superimposition of the $\mathrm{mDia}_{\mathrm{N}} \Delta \mathrm{G}$ from this structure (grey) and the structures of unbound (yellow) and Rho-bound (blue) $\mathrm{mDia}_{\mathrm{N}}$ (Otomo et al, 2005b; Rose et al, 2005b), leaving out RhoC and $\mathrm{GBD}_{\mathrm{N}}$. (C) Stereo view of the interface between the ARR and DAD, highlighting residues mentioned in the text. (D) Conservation of residues, where the intensity of red indicates the degree of conservation (accession numbers of compared proteins: mDia1 O08808, mDia2 Q9Z207; mDia3 O70566; hDia1 O60610; hDia2 O60879; DAAM1 human Q9Y4D1; DAAM1 mouse Q8BPM0; DAAM2 human Q86T65; DAAM2 mouse Q80U19; Gallus gallus Dia Q9DEH3; E. histolytica Dia Q514T8; DroMe Dia P48608); dashed lines show the possible paths of the N- and C-terminal extensions of the polypeptide chain; Asp366, Ile259, Ala256, Lys213 and Asn217 are highlighted. (E) Electrostatic potential of the mDia ${ }_{N} \Delta$ G surface as calculated with APBS (Baker et al, 2001), position of the DCR and the suspected polypeptide path from N to C as indicated.

slightly (Figure 5A and B). The N-terminal Gly1180 in DAD, the first residue visible in the structure, would probably clash with $\mathrm{GBD}_{\mathrm{N}}$ upon Rho binding. Thr1179, which is not visible in the structure, would definitely clash with RhoC in any reasonable orientation that we can model into the structure (Figure 5B). In addition, the negative charges of Asp1183 and
Glu1187 on $\mathrm{DAD}_{1145-1200}$ would experience electrostatic repulsion from the negative charges of Glu64, Asp65 and Asp67 from Rho. Although this might be sufficient to mediate release of $\mathrm{DAD}$, it might well be that additional residues on the $\mathrm{N}$ - or C-terminal extension of the DAD peptide, which we cannot identify in the current structure, would also interfere 
Table III Refinement statistics

\begin{tabular}{|c|c|c|c|}
\hline \multicolumn{2}{|c|}{$\begin{array}{l}\text { Resolution }(\AA) \\
\text { Reflections (working/test set) } \\
\text { Number of atoms } \\
R_{\text {work }}(\%)^{\mathrm{a}} \\
\bar{R}_{\text {free }}(\%)^{\mathrm{b}} \\
\text { Mean } B \text {-value }\left(\AA^{2}\right)\end{array}$} & $\begin{array}{l}20-3.3 \\
17565 / 925 \\
4966 \\
28.8 \\
36.4 \\
92.2\end{array}$ & \\
\hline \multicolumn{2}{|c|}{$\begin{array}{l}\text { R.m.s. deviations from standard geo- } \\
\text { metryc } \\
\text { Bond length }(\AA) \\
\text { Bond angle (deg) } \\
\text { Torsion angle (deg) }\end{array}$} & $\begin{array}{l}5031 / 0.010 / 0.02 \\
6770 / 1.248 / 1.9 \\
615 / 5.907 / 5.0\end{array}$ & ./weight \\
\hline \multicolumn{2}{|c|}{$\begin{array}{l}\text { Isotropic thermal factor restraints } \\
\text { Main-chain bond refined atoms }\left(\AA^{2}\right) \\
\text { Main-chain angle refined atoms }\left(\AA^{2}\right) \\
\text { Side-chain bond refined atoms }\left(\AA^{2}\right) \\
\text { Side-chain angle refined atoms }\left(\AA^{2}\right)\end{array}$} & \multicolumn{2}{|c|}{$\begin{array}{l}\text { Counts/r.m.s.d./wei } \\
3192 / 0.411 / 1.500 \\
4974 / 0.718 / 2.000 \\
2018 / 0.694 / 3.000 \\
1796 / 1.132 / 4.500\end{array}$} \\
\hline \multicolumn{4}{|c|}{$\begin{array}{l}{ }^{\mathrm{a}} R_{\text {work }}=\sum\left|F_{\mathrm{o}}-F_{\mathrm{c}}\right| / \sum F_{\mathrm{o}} \text { where } F_{\mathrm{o}} \text { and } F_{\mathrm{c}} \text { are the observed and } \\
\text { calculated structure factor amplitudes. } \\
{ }^{\mathrm{b}} R_{\text {free is claculated similarly to } R_{\text {work }} \text { using the test set reflections. }} \\
{ }^{\mathrm{c}} \text { For definition, see REFMAC5 (www.ysbl.york.ac.uk/ garib/ } \\
\text { refmac/index.html). }\end{array}$} \\
\hline mDia Molecules compared & Compared & $\begin{array}{l}\text { Number of } \\
\text { atoms compared }\end{array}$ & $\underset{(\AA)}{R . m_{\delta} \text { s.d. }}$ \\
\hline DAD-bound/Rho-bound & $\mathrm{C} \alpha$ & 246 & 0.87 \\
\hline DAD-bound/unbound & $\mathrm{C} \alpha$ & 226 & 0.7 \\
\hline Rho-bound/unbound & $\mathrm{C} \alpha$ & 241 & 0.8 \\
\hline DAD-bound/Rho-bound & All atoms & 2108 & 1.514 \\
\hline DAD-bound/unbound & All atoms & 2015 & 2.286 \\
\hline Rho-bound/unbound & All atoms & 2064 & 2.078 \\
\hline
\end{tabular}

with Rho. The most likely residues are those on the $\mathrm{N}$-terminal end of DAD, which, although not making any contribution to $\mathrm{mDia}_{\mathrm{N}}$ binding (Figure 2), might nevertheless interfere with Rho binding.

For a quantitative analysis of competitive binding by ITC, the $\mathrm{mDia}_{\mathrm{N}} \bullet \mathrm{DAD}_{1145-1200}$ complex $\left(30 \mu \mathrm{M} \mathrm{mDia}_{\mathrm{N}}\right.$; $\left.60 \mu \mathrm{M} \mathrm{DAD}_{1145-1200}\right)$ was titrated with RhoA•GppNHp (Figure 6A). The primary heat changes were fitted using a simple one-site binding model. DAD is released with an apparent affinity $\mathrm{IC}_{50}$ of $29 \mu \mathrm{M}$, with a molar ratio of $1: 1$ for the RhoA $\bullet$ GpNHp mDia $_{\mathrm{N}}$ binding (Figure 6A). The enthalpy of the reaction was $-9.8 \mathrm{kcal} \mathrm{mol}^{-1}$ (Figure 6A), which is close to (but with opposite sign) the highly endothermic $\Delta \mathrm{H}$ $\left(+10.6 \mathrm{kcal} \mathrm{mol}^{-1}\right)$ obtained for the binding of $\mathrm{DAD}_{1145-1200}$ to $\mathrm{mDia}_{\mathrm{N}}$ (Figure 2A). Direct ITC measurements of RhoA $\bullet$ GppNHp binding to $\mathrm{mDia}_{\mathrm{N}}$ at different concentrations and temperatures did not lead to a measurable signal. This could be due to the binding of RhoA $\bullet$ GppNp to $\mathrm{mDia}_{\mathrm{N}}$ having an endothermic and an exothermic part, which neutralise each other (e.g. due to conformational change), or that the high-affinity binding reaction is indeed solely entropy driven.

To see if Rho has an active dissociating effect on the dissociation of the $\mathrm{mDia}_{\mathrm{N}} \bullet \mathrm{DAD}$ complex, a preformed complex between mDia $_{\mathrm{N}}$ and F-DAD was mixed with increasing concentrations of either RhoA $\bullet \mathrm{GppNHp}$ or RhoA $\bullet \mathrm{GDP}$, in the presence of a 100 -fold excess nonlabelled $\mathrm{DAD}_{1145-1200}$ to
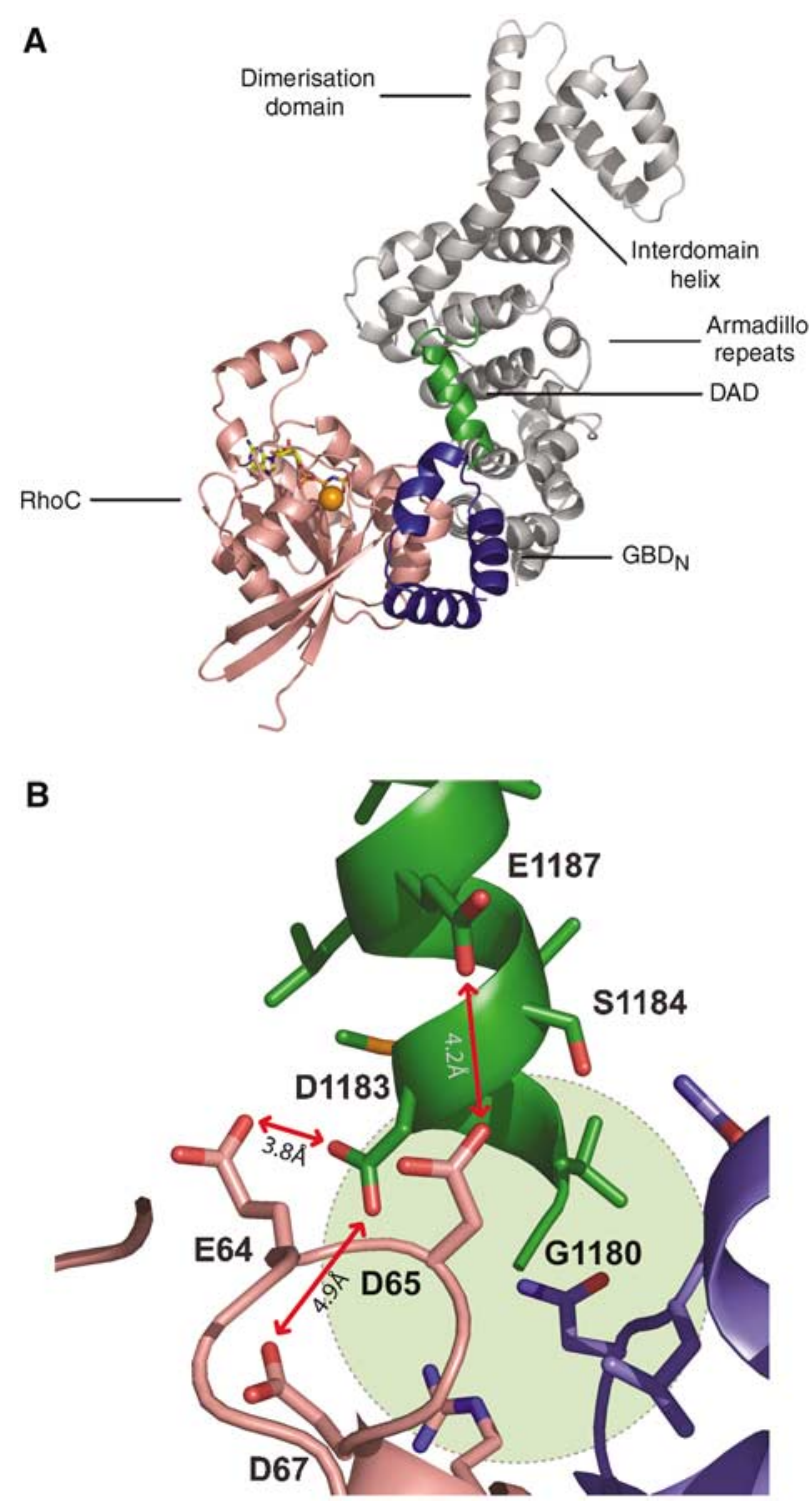

Figure 5 Structural model for release of DAD by Rho binding. (A) Model of a complex of $\mathrm{mDia}_{\mathrm{N}}$ with Rho GTP and the DCR, using the previous RhoC complex structure (Rose et al, 2005b) and the DAD complex structure obtained here and the superimposition shown in Figure 4B. (B) Details of the electrostatic repulsion between DAD and Rho in a proposed ternary $\mathrm{mDia}_{\mathrm{N}}-\mathrm{Rho}-\mathrm{DAD}$ complex; the steric clash on inserting the next DAD residue, Thr1179, is indicated by a green circle.

silence the back reaction. Dissociation was followed by stopped-flow. RhoA $\bullet$ GppNHp does indeed accelerate the dissociation of the $\mathrm{mDia}_{\mathrm{N}} \bullet \mathrm{F}$-DAD complex, with a threefold increase over the concentration range used, while RhoA $\bullet$ GDP does not (Figure 6B). This argues for an active displacement mechanism by the binding of RhoA $\bullet$ GTP in the release of autoinhibition.

\section{Discussion}

In the absence of a full-length protein structure, it is difficult to delineate the structural and functional boundaries of the FH2 and DAD domains of mDia. Here, we show that there is a DAD core region encompassing residues 1180-1195, 

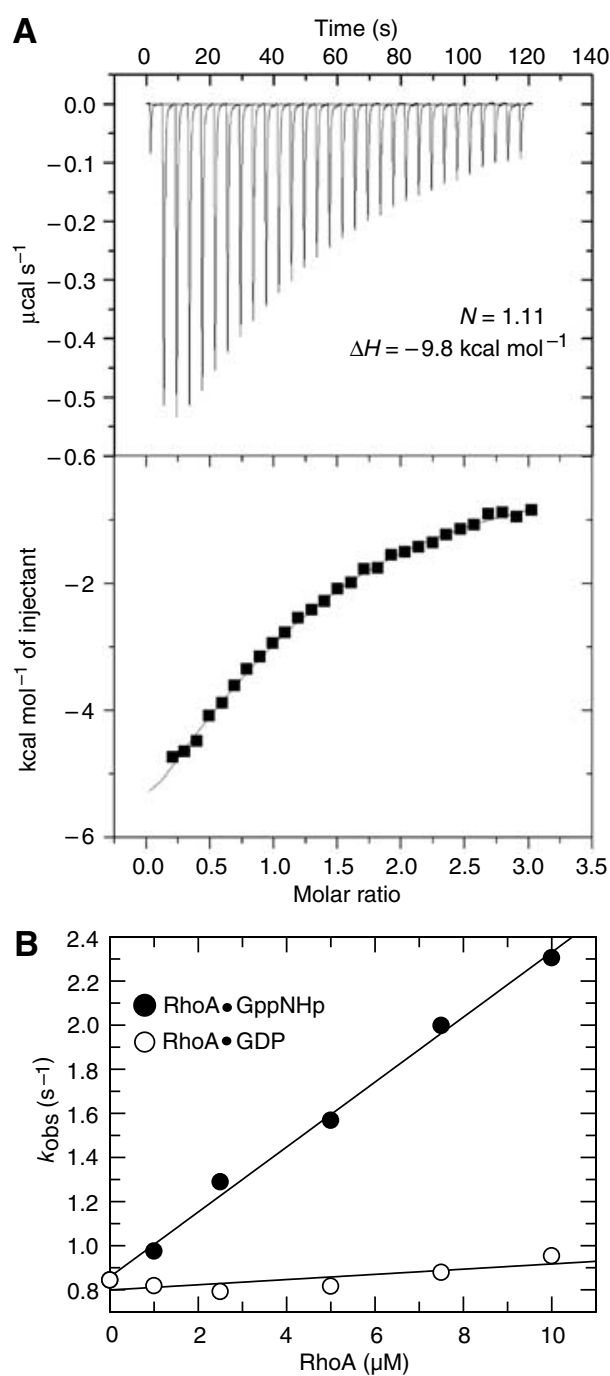

Figure 6 Effect of Rho binding on the $\mathrm{mDia}_{\mathrm{N}} \bullet \mathrm{DAD}_{1145-1200} \mathrm{com}-$ plex. (A) ITC analysis of the dissociation $\mathrm{mDia}_{\mathrm{N}}-\mathrm{DAD}_{1145-1200}$ complex $\left(30 \mu \mathrm{M} \mathrm{mDia}_{\mathrm{N}} ; 60 \mu \mathrm{M} \mathrm{DAD}_{1145-1200}\right)$ by titration with $400 \mu \mathrm{M}$ RhoA $\bullet \mathrm{GppNHp}$, with upper and lower panels as in Figure $2 \mathrm{~A}$ and $\mathrm{B}$. (B) Dissociation of DAD from the $\mathrm{mDia}_{\mathrm{N}}-\mathrm{DAD}_{1145-1200}$ complex is followed by fluorescence as described in Figure 1D, in the presence of increasing amounts of RhoA $\bullet \mathrm{GppNHp}(\bullet)$ or RhoA $\bullet$ GDP $(\bigcirc)$. The dissociation rate constants $k_{\text {obs }}$ are plotted against the concentration of Rho.

which represents the smallest functional and structural unit of autoinhibition. This core region forms a helical structure and binds to a highly conserved patch of residues on the ARR of $\mathrm{mDia}_{\mathrm{N}}$ (Figure 4D). No electron density could be detected for the rest of the peptide that was used in crystallisation, suggesting that this part is either partially or fully unstructured and/or does not contribute significantly to binding, or that the high salt crystallisation conditions prevent chargecharge interactions, as observed, that is, for the interaction of the DEDDL motif of Ran with its basic patch (Vetter et al, 1999; Scheffzek et al, 2002).

Our biochemical data (Figure 2C) show that a number of basic residues following Phe1195 do have a pronounced influence since deletion of residues 1197-RKRG-1200 leads to a 13 -fold reduction in affinity. Further truncation of a 36mer peptide (residues 1165-1200) to a 22mer (1175-1196) on the $\mathrm{C}$-terminal side and another set of basic residues on the N-terminal side drastically reduces the affinity (36mer: $K_{\mathrm{D}}=194 \mathrm{nM} ; 22 \mathrm{mer}: K_{\mathrm{D}}=15 \mu \mathrm{M}$ ). This suggests that there should be additional contacts between DAD and ARR, although the mutation of the conserved N-terminally located Lys1152 on DAD or Asp366 on ARR alone did not decrease affinity (Figure 2C and Table I). One half of the surface of $\mathrm{mDia}_{\mathrm{N}}$ is strongly negatively charged, so it could represent a binding site for the two basic patches flanking the DAD-core region (DCR) (Figure $4 \mathrm{D}$ and $\mathrm{E}$ ). The structure of the $\mathrm{N}$-terminal 16 residues of $\mathrm{DAD}_{1145-1200}$ has been solved as part of the FH2 structure and is helical (Shimada et al, 2004). The fact that it is not visible in the structure indicates that there is no significant interaction of this part of the $\mathrm{FH} 2$ domain with the ARR.

While the binding of Rho to $\mathrm{mDia}_{\mathrm{N}}$ does not involve any apparent enthalpy change, the binding of DAD to $\mathrm{mDia}_{N}$ is highly endothermic, and is compensated by a large favourable entropy change. There is corresponding heat released on binding of Rho to the $\mathrm{mDia}_{\mathrm{N}} \bullet \mathrm{DAD}$ complex, showing that the release of $\mathrm{DAD}$ is at least enthalpically favoured. Conformational changes of $\mathrm{GBD}_{\mathrm{N}}$ upon binding of $\mathrm{DAD}_{1145-1200}$ to $\mathrm{mDia}_{\mathrm{N}}$ can be ruled out as an explanation for the positive $\Delta \mathrm{H}$, since three different structures of the $\mathrm{N}$ terminal region in three different binding states superimpose very well. A conformational change of DAD, such as the kink of the helix observed in the structure, might contribute, but no structure of the unbound DAD fragment is available right now. The highly favourable entropy change argues for hydrophobic contacts as the major contribute to binding, and against loss of conformational flexibility on binding, since positive $\Delta S$ values indicate exclusion of water molecules from the interface. Thermodynamic analysis of the DAD mutants shows that a weaker binding is a result of both lower enthalpy and entropy, another example of the frequently observed enthalpy-entropy compensation in protein-protein interactions (Table I) (Frisch et al, 1997).

How then does Rho induce the dissociation of the mDia $_{N} \bullet$ DAD complex? The structure of the mDia $_{N} \bullet$ RhoC complex has shown that the Rho binding site consists of two subdomains, $\mathrm{GBD}_{\mathrm{N}}$ and the ARR (Rose et al, 2005b), which are both required for tight binding of Rho GTP (Figure 5A). $\mathrm{GBD}_{\mathrm{N}}$ is only loosely connected to the ARR, suggesting that it can easily change its orientation relative to it when not bound to Rho. We would thus propose a model (Figure 7) whereby the $\mathrm{GBD}_{\mathrm{N}}$ in the autoinhibited state is in a conformation that would allow Rho•GTP binding such that it would not interfere with DAD. Rho binds to the large hydrophobic patch on the $\mathrm{GBD}_{\mathrm{N}}$ via switch I and a part of switch II, and forms a low-affinity ternary RhoC $\bullet \mathrm{DAD}-\mathrm{mDia}_{\mathrm{N}}$ complex. In the second step, a conformational change occurs, which positions Rho to make additional contact to the ARR of $\mathrm{mDia}_{\mathrm{N}}$, as observed in the structure of the RhoC $\bullet \mathrm{mDia}_{\mathrm{N}}$ complex. The movement of the $\mathrm{GBD}_{\mathrm{N}}$ towards this conformation would firstly induce long-range electrostatic repulsion by similar charges on DAD (Asp1183, Glu1187) and Rho (Glu64, Asp65, Asp67); secondly, short-range steric clashes would induce the release of DAD from the regulatory region of mDia to form a binary tight complex. This two-step binding model of releasing the $\mathrm{mDia}_{\mathrm{N}}-\mathrm{DAD}$ interaction by active Rho is comparable to the GEF-catalysed nucleotide exchange on Ras-like proteins, where GEF goes from a weak binding to a strong binding state, thereby inducing a transition from a 


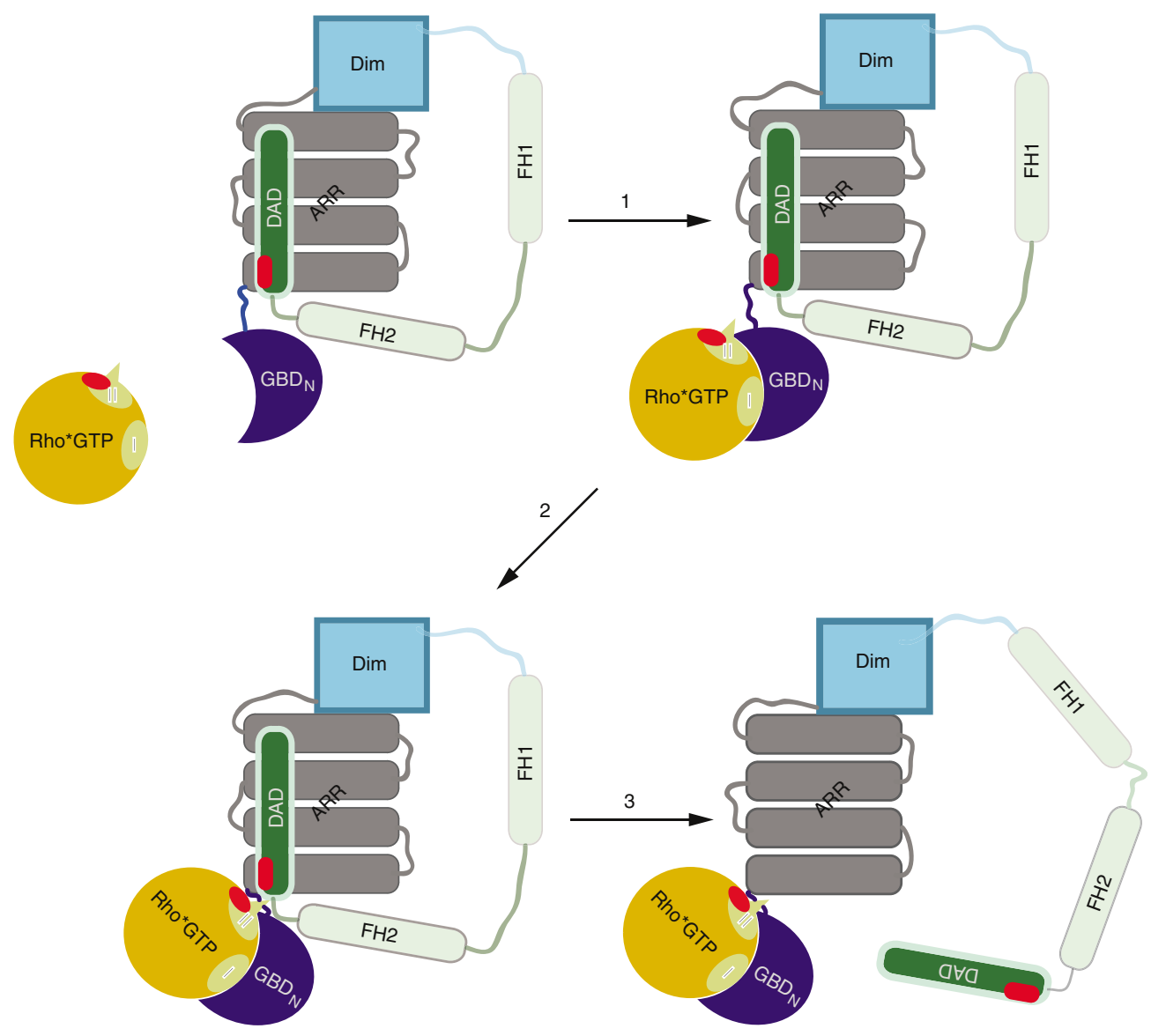

Figure 7 Schematic two-step-binding model of DAD release from the regulatory region of mDial by Rho $\bullet$ GTP, as described in the text.

high- to a low-affinity state of the nucleotide (Vetter and Wittinghofer, 2001).

In our studies, the equilibrium of the displacement reaction of the DAD•mDia ${ }_{N}$ complex by Rho $\bullet$ GTP is mostly on the side of the Rho- $\mathrm{mDia}_{\mathrm{N}}$ complex due to a 18-fold higher affinity. In the full-length mDia protein the former interaction is intramolecular, even when one considers that the protein is a dimer and the DAD binding occurs in trans between the subunits. Thus, release of autoinhibition is more complex in this case, and preliminary experiments with constructs containing the $\mathrm{FH} 2$ domain in addition to $\mathrm{DAD}$ and $\mathrm{mDia}_{\mathrm{N}}$ indicate that, in this case, Rho binding does not fully activate the actin polymerisation activity of FH2 (Li and Higgs 2003, 2005). Full activation might thus require an additional step that shifts the equilibrium towards the active state. While our data fully describe the structural requirements of mDia autoinhibition and its release by Rho GTP, further experiments with full-length mDia are probably required to understand the energetic requirements for activation.

\section{Materials and methods}

\section{Recombinant proteins}

Proteins were expressed as GST fusions using the vector pGEX-4T1 (Amersham Biociences). The bicistronic $\mathrm{mDia}_{\mathrm{N}} \Delta \mathrm{G}-\mathrm{DAD}_{1145-1200}$ construct was generated using an overlapping PCR. For expression, E. coli BL21DE3 cells were grown to an $\mathrm{OD}_{600}$ of $0.7\left(37^{\circ} \mathrm{C}\right.$, 160 r.p.m.), induced with $100 \mu \mathrm{M}$ of isopropyl- $\beta$-D-thiogalactopyranoside (IPTG) overnight at $20^{\circ} \mathrm{C}$. The cells were harvested, suspended in buffer A $(50 \mathrm{mM}$ Tris- $\mathrm{HCl} \mathrm{pH} 7.5,150 \mathrm{mM} \mathrm{NaCl}$, $2 \mathrm{mM} \beta$-mercaptoethanol) containing $0.1 \mathrm{mM}$ phenylmethylsulphonyl fluoride (PMSF) and 2 mM EDTA. Cells were lysed by sonication or microfluidizing, the extract applied to a GSH-Sepharose column (Amersham Biosciences) and the column washed with buffer $\mathrm{B}$ (50 mM Tris- $\mathrm{HCl}, \mathrm{pH} 7.5,300 \mathrm{mM} \mathrm{NaCl}, 2 \mathrm{mM} \beta$-mercaptoethanol). The fusion protein was digested with $5 \mathrm{U}$ thrombin (serva) per $\mathrm{mg}$ of GST-fusion protein on the column overnight at $4^{\circ} \mathrm{C}$. The final purification was carried out with size exclusion chromatography in buffer B using a Superdex S75 for $\mathrm{mDia}_{\mathrm{N}}$ or S200 for the DAD fragments. For the $\mathrm{mDia}_{\mathrm{N}} \Delta \mathrm{G}-\mathrm{DAD} \mathrm{D}_{1145-1200}$ complex used for crystallisation, the buffer used for gel filtration contained $20 \mathrm{mM}$ HEPES, pH 7.1, $300 \mathrm{mM} \mathrm{NaCl}$ and $2 \mathrm{mM} \beta$-mercaptoethanol. For selenomethionine labelling, $\mathrm{mDia}_{\mathrm{N}} \Delta \mathrm{G}-\mathrm{DAD}_{1145-1200}$ was expressed in LeMaster medium containing $0.1 \mathrm{~g} / \mathrm{l} \mathrm{Se-Met}$. The gel filtration buffer contained $20 \mathrm{mM}$ HEPES, pH 7.1, $300 \mathrm{mM} \mathrm{NaCl}$ and $10 \mathrm{mM}$ $\beta$-mercaptoethanol.

Point mutations were introduced into DAD by the QuickChange protocol (Stratagene) or the PCR mutagenesis protocol of Picard and Bock (1997). Mutant proteins were purified like the wild-type proteins. Concentrations of $\mathrm{mDia}_{\mathrm{N}}$ and $\mathrm{mDia}_{\mathrm{N}} \Delta \mathrm{G}$ were determined by absorption at $280 \mathrm{~nm}$ using the extinction coefficient deduced from the sequence. Rho was purified and loaded with GppNHp as described elsewhere (Rose et al, 2005b).

\section{Synthesised DAD peptides and constructs}

DAD peptides comprising residues $1175-1196$ and the N-terminally AMCA-labelled (7-amino-4-methylcoumarin-3-acetic acid (AMCA)) peptide were synthesised by Biosynthan, Berlin. The Iaedans labelling of $100 \mu \mathrm{M}$ of $\mathrm{DAD}_{1145-1200}$ carrying a C-terminal Cys in buffer C (50 mM Tris- $\mathrm{HCl}, \mathrm{pH} 7.5,300 \mathrm{mM} \mathrm{NaCl}, 10 \mathrm{mM}$ ascorbic acid) was carried out by incubating it overnight $\left(4^{\circ} \mathrm{C}\right)$ with a 3-5fold excess of the fluorophore (5-((((2-iodoacetyl)amino)ethyl)amino)naphthalene-1-sulfonic acid (1.5-Iaedans)) and exchanging the 
buffer to buffer B. Concentrations of the DAD fragments were determined by the methods of Ehresmann et al (1973) and Ellman (1958).

\section{Stopped-flow kinetics}

The experiments were performed at $20^{\circ} \mathrm{C}$ using a SX18 MW Applied Photophysics apparatus (Leatherhead, UK). The Aedans fluorophore (Molecular Probes) was excited at $336 \mathrm{~nm}$ with a bandpass of $6.4 \mathrm{~nm}$. Emission (at $490 \mathrm{~nm}$ ) was recorded using a $408 \mathrm{~nm}$ cut-off filter. All measurements were carried out with a final concentration of $100 \mathrm{nM}$ of F-DAD and $\mathrm{mDia}_{\mathrm{N}}-\mathrm{F}-\mathrm{DAD}$. Increasing concentrations of $\mathrm{mDia}_{\mathrm{N}}(1-15 \mu \mathrm{M})$ and RhoA GppNHp/RhoA GDP $(1-10 \mu \mathrm{M})$ were used in the experiments using pseudo-first-order conditions. The observed fluorescence transients were fitted to a singleexponential function to obtain $k_{\text {obs }}$. The association rate constant $k_{\text {on }}$ was derived from the slope of $k_{\text {obs }}$ versus protein concentration. The dissociation rate constants were obtained by mixing a preformed $100 \mathrm{nM} \mathrm{mDia}_{\mathrm{N}}-\mathrm{F}$-DAD complex with a 100 -fold excess of unlabelled $\mathrm{DAD}_{1145-1200}$. When investigating the dissociation acceleration by RhoA, RhoA $\bullet$ GppNHp or RhoA $\bullet$ GDP was used together with a 100 -fold excess of unlabelled $\mathrm{DAD}_{1145-1200}$. All measurements were carried out in buffer $\mathrm{B}$, additionally containing $5 \mathrm{mM} \mathrm{MgCl}_{2}$ in the RhoA experiments. GraFit 3.0-GraFit 5.0 was used for data analysis.

\section{ITC measurements}

The interaction of $\mathrm{mDia}_{\mathrm{N}}$ and $\mathrm{DAD}$, characterisation of $\mathrm{DAD}$ and $\mathrm{mDia}_{\mathrm{N}}$ mutants, and analysis of different DAD constructs was performed by ITC based on Wiseman et al (1989) (MicroCal ${ }^{\mathrm{TM}}$; VPITC microcalorimeter). All measurements were carried out in buffer B. Concentrations of $0.02-3.7 \mathrm{mM}$ DAD or $400 \mu \mathrm{M}$ RhoA $\bullet \mathrm{GppNHp}$ (syringe) were stepwise injected to the $20-280 \mu \mathrm{M} \mathrm{mDia}_{\mathrm{N}}$ or to the $30 \mu \mathrm{M}$ mDia $_{\mathrm{N}}-60 \mu \mathrm{M} \mathrm{DAD}_{1145-1200}$ complex solution (cell), respectively. The heating power per injection was observed over the reaction time until equilibrium was reached. The data were analysed using the software provided by the manufacturer.

\section{Fluorescence equilibrium titration and polarisation \\ measurements}

All experiments were performed by using a FluoroMax II spectrofluorimeter at $20^{\circ} \mathrm{C}$. Polarisation experiments were carried out using a polarisation filter (SPEX Instruments, $\mathrm{NJ}$ ), buffer $\mathrm{B}$ plus $5 \%$ DMSO plus $5 \mathrm{mM} \mathrm{MgCl}$ if RhoA was used. The AMCA fluorophore was excited at $353 \mathrm{~nm}$, the Aedans fluorophore at $336 \mathrm{~nm}$. The emission was detected at $442 \mathrm{~nm}$ for the AMCA and at $490 \mathrm{~nm}$ for the Aedans fluorophore. Fluorescence titration experiments were performed in buffer B plus $0.001 \%$ Tween 20 . The AMCA- or Aedans-labelled DAD fragments $(100 \mathrm{nM})$ were preincubated until the baseline was stable. In addition, DDia $_{N}$ was added stepwise (0.017-67 $\mu \mathrm{M})$, mixed rapidly and the fluorescence was followed until the signal did not change anymore. The relative fluorescence

\section{References}

Alberts AS (2001) Identification of a carboxyl-terminal Diaphanousrelated formin homology protein autoregulatory domain. $J$ Biol Chem 276: 2824-2830

Baker NA, Sept D, Joseph S, Holst MJ, McCammon JA (2001) Electrostatics of nanosystems: application to microtubules and the ribosome. Proc Natl Acad Sci USA 98: 10037-10041

Bedford MT, Chan DC, Leder P (1997) FBP WW domains and the Abl SH3 domain bind to a specific class of proline-rich ligands. EMBO J 16: 2376-2383

Bishop AL, Hall A (2000) Rho GTPases and their effector proteins. Biochem J 348: 241-255

Buck M, Xu W, Rosen MK (2004) A two-state allosteric model for autoinhibition rationalizes WASP signal integration and targeting J Mol Biol 338: 271-285

Castrillon DH, Wasserman SA (1994) Diaphanous is required for cytokinesis in Drosophila and shares domains of similarity with the products of the limb deformity gene. Development $\mathbf{1 2 0}$ 3367-3377

Chook YM, Blobel G (1999) Structure of the nuclear transport complex karyopherin-beta2-Ran xGppNHp. Nature 20: 230-237 yield or polarisation was plotted against the protein concentration and the obtained curve was analysed by fitting a quadratic function to the data as described by Herrmann and Nassar (1996). For data analysis, Grafit 3.0-Grafit 5.0 was used.

\section{Crystallisation and structure determination}

Selenomethionine crystals of the $\mathrm{GBD}_{136-451}-\mathrm{DAD}_{1145-1200}$ complex were grown in buffer $\mathrm{D}$ containing $3.7 \mathrm{M}$ Na formate, $\mathrm{pH} 7.1$, $100 \mathrm{mM}$ HEPES, pH 7.1 and 4.0\% PEG5000MME, using the hanging drop/vapour diffusion method. The protein was solved in buffer containing $20 \mathrm{mM}$ HEPES, $\mathrm{pH} 7.1,300 \mathrm{mM} \mathrm{NaCl}$ and $10 \mathrm{mM} \beta$ mercaptoethanol. In all, $1 \mu \mathrm{l}$ of protein solution of various concentrations $(2.5 \mu \mathrm{g} / \mu \mathrm{l}, 5 \mu \mathrm{g} / \mu \mathrm{l}, 10 \mu \mathrm{g} / \mu \mathrm{l})$ was mixed with the reservoir solution (buffer D). After 1 day, crystals that had a size of $200 \times 100 \times 100 \mu \mathrm{M}$ grew at $20^{\circ} \mathrm{C}$. These crystals were flash frozen in liquid nitrogen using buffer $\mathrm{D}$ as cryoprotectant.

Data-set collection has been performed at the Swiss Light Source, Paul Scherrer Institut, Villigen, Switzerland (Table II). A Se-Met data set was collected at $100 \mathrm{~K}$ on beam line PXII at a wavelength of $0.95 \AA$, using a Mar225 CCD detector. The detector distance was $350 \mathrm{~mm}$, the oscillation range was $0.5^{\circ}$ and 404 frames were collected. Data were indexed, integrated and scaled with the XDS package (Kabsch, 1993).

Crystals belonged to the hexagonal space group $\mathrm{P}_{1} 22$ and contained two $\mathrm{mDia}_{\mathrm{N}} \Delta \mathrm{G}-\mathrm{DAD}_{1145-1200}$ heterodimers in the asymmetric unit. Initial phases were determined with the program Phaser (McCoy et al, 2005) using residues 132-369 of chain B of the $\mathrm{mDia}_{\mathrm{N}} \bullet$ RhoC structure (PDB: 1Z1C) as a template and searching for two molecules. The program Coot (Emsley and Cowtan, 2004) was used to build the model into the $2 F_{\mathrm{o}}-F_{\mathrm{c}}$ and $F_{\mathrm{o}}-F_{\mathrm{c}}$ maps in iterative rounds of NCS refinement with REFMAC (Table III) (Murshudov et al, 1999). The final model has a good geometry with $98 \%$ of all residues in the allowed regions of the Ramachandran plot, as judged by the program Procheck (Laskowski et al, 1993). All structure figures were prepared with PyMOL (DeLano, 2002).

\section{Supplementary data}

Supplementary data are available at The EMBO Journal Online.

\section{Acknowledgements}

We are grateful to the machine and beamline groups, whose outstanding efforts have made these experiments possible. We thank Alex Berndt and Wulf Blankenfeldt for data collection, Michael Weyand for help in X-ray crystallography, Dorothee Kühlmann and Caroline Koerner for expert technical assistance, and Rita Schebaum for expert secretary assistance. The structure factors and coordinates were deposited in the PDB under the ID 2BAP. AW thanks the Deutsche Forschungsgemeinschaft for financial support (SFB 642).

Copeland JW, Treisman R (2002) The Diaphanous-related formin mDial controls serum response factor activity through its effects on actin polymerization. Mol Biol Cell 13: 4088-4099

DeLano WL (2002) The PyMOL User's Manual. San Carlos, CA, USA: DeLano Scientific

Ehresmann B, Imbault P, Weil JH (1973) Spectrophotometric determination of protein concentration in cell extracts containing tRNA's and rRNA's. Anal Biochem 54: 454-463

Eklof Spink K, Fridman SG, Weis WI (2001) Molecular mechanisms of beta-catenin recognition by adenomatous polyposis coli revealed by the structure of an APC-beta-catenin complex. EMBO J 20: $6203-6212$

Ellman GL (1958) A colorimetric method for determining low concentrations of mercaptans. Arch Biochem Biophys 74: 443-450

Emsley P, Cowtan K (2004) Coot: model-building tools for Molecular Graphics. Acta Crystallogr 60: 2126-2132

Etienne-Manneville S, Hall A (2002) Rho GTPases in cell biology. Nature 420: 629-635

Evangelista M, Zigmond S, Boone C (2003) Formins: signaling effectors for assembly and polarization of actin filaments. $J$ Cell Sci 116: 2603-2611 
Frisch C, Schreiber G, Johnson CM, Fersht AR (1997) Thermodynamics of the interaction of barnase and barstar: changes in free energy versus changes in enthalpy on mutation. J Mol Biol 267: 696-706

Graham TA, Weaver C, Mao F, Kimelman D, Xu W (2000) Crystal structure of a beta-catenin/Tcf complex. Cell 103: 885-896

Harris ES, Li F, Higgs HN (2004) The mouse formin, FRLalpha, slows actin filament barbed end elongation, competes with capping protein, accelerates polymerization from monomers, and severs filaments. J Biol Chem 279: 20076-20087

Herrmann C, Nassar N (1996) Ras and its effectors. Prog Biophys Mol Biol 66: 1-41

Higashida C, Miyoshi T, Fujita A, Oceguera-Yanez F, Monypenny J, Andou Y, Narumiya S, Watanabe N (2004) Actin polymerizationdriven molecular movement of mDia1 in living cells. Science 303: 2007-2010

Higgs HN (2005) Formin proteins: a domain-based approach. Trends Biochem Sci 30: 342-353

Higgs HN, Peterson KJ (2005) Phylogenetic analysis of the formin homology 2 domain. Mol Biol Cell 16: 1-13

Ishizaki T, Morishima Y, Okamoto M, Furuyashiki T, Kato T, Narumiya S (2001) Coordination of microtubules and the actin cytoskeleton by the Rho effector mDia1. Nat Cell Biol 3: 8-14

Kabsch W (1993) Automatic processing of rotation diffraction data from crystals of initially unknown symmetry and cell constants. J Appl Crystallogr 26: 795-800

Kato T, Watanabe N, Morishima Y, Fujita A, Ishizaki T, Narumiya S (2001) Localization of a mammalian homolog of diaphanous, mDial, to the mitotic spindle in HeLa cells. J Cell Sci 114: 775-784

Kovar DR, Pollard TD (2004) Progressing actin: formin as a processive elongation machine. Nat Cell Biol 6: 1158-1159

Kovar DR, Wu JQ, Pollard TD (2005) Profilin-mediated competition between capping protein and formin Cdc12p during cytokinesis in fission yeast. Mol Biol Cell 16: 2313-2324

Laskowski RA, Moss DS, Thornton JM (1993) Main-chain bond lengths and bond angles in protein structures. J Mol Biol 231: 1049-1067

Lei M, Lu W, Meng W, Parrini MC, Eck MJ, Mayer BJ, Harrison SC (2000) Structure of PAK1 in an autoinhibited conformation reveals a multistage activation switch. Cell 102: 387-397

Lei M, Robinson MA, Harrison SC (2005) The active conformation of the PAK1 kinase domain. Structure 13: 769-778

Leung DW, Rosen MK (2005) The nucleotide switch in Cdc42 modulates coupling between the GTPase-binding and allosteric equilibria of Wiskott-Aldrich syndrome protein. Proc Natl Acad Sci USA 102: $5685-5690$

Li F, Higgs HN (2003) The mouse formin mDial is a potent actin nucleation factor regulated by autoinhibition. Curr Biol 13: $1335-1340$

Li F, Higgs HN (2005) Dissecting requirements for auto-inhibition of actin nucleation by the formin, mDia1. J Biol Chem 280: 6986-6992

Macias MJ, Wiesner S, Sudol M (2002) WW and SH3 domains, two different scaffolds to recognize proline-rich ligands. FEBS Lett 513: $30-37$

Maesaki R, Ihara K, Shimizu T, Kuroda S, Kaibuchi K, Hakoshima T (1999) The structural basis of Rho effector recognition revealed by the crystal structure of human RhoA complexed with the effector domain of PKN/PRK1. Mol Cell 4: 793-803

McCoy AJ, Grosse-Kunstleve RW, Storoni LC, Read RJ (2005) Likelihood-enhanced fast translation functions. Acta Crystallogr 61: 458-464

Millard TH, Sharp SJ, Machesky LM (2004) Signalling to actin assembly via the WASP (Wiskott-Aldrich syndrome protein)family proteins and the Arp2/3 complex. Biochem J 380: 1-17

Murshudov GN, Lebedev A, Vagin AA, Wilson KS, Dodson EJ (1999) Efficient anisotropic refinement of macromolecular structures using FFT. Acta Crystallogr 55: 247-255

Otomo T, Otomo C, Tomchick DR, Machius M, Rosen MK (2005b) Structural basis of Rho GTPase-mediated activation of the formin mDia1. Mol Cell 18: 273-281
Otomo T, Tomchick DR, Otomo C, Panchal SC, Machius M, Rosen MK (2005a) Structural basis of actin filament nucleation and processive capping by a formin homology 2 domain. Nature 433: 488-494

Ozaki-Kuroda K, Yamamoto Y, Nohara H, Kinoshita M, Fujiwara T, Irie K, Takai Y (2001) Dynamic localization and function of Bnilp at the sites of directed growth in Saccharomyces cerevisiae. Mol Cell Biol 21: 827-839

Pantaloni D, Le Clainche C, Carlier MF (2001) Mechanisim of actinbased motility. Science 292: 1502-1506

Picard V, Bock SC (1997) Rapid and efficient one-tube PCR-based mutagenesis method. Methods Mol Biol 67: 183-188

Pollard TD, Borisy GG (2003) Cellular motility driven by assembly and disassembly of actin filaments. Cell 112: 453-465

Pring M, Evangelista M, Boone C, Yang C, Zigmond SH (2003) Mechanism of formin-induced nucleation of actin filaments. Biochemistry 42: 486-496

Pruyne D, Evangelista M, Yang C, Bi E, Zigmond S, Bretscher A, Boone C (2002) Role of formins in actin assembly: nucleation and barbed-end association. Science 297: 612-615

Quinlan ME, Heuser JE, Kerkhoff E, Mullins RD (2005) Drosophila Spire is an actin nucleation factor. Nature 433: 382-388

Romero S, Le Clainche C, Didry D, Egile C, Pantaloni D, Carlier MF (2004) Formin is a processive motor that requires profilin to accelerate actin assembly and associated ATP hydrolysis. Cell 119: 419-429

Rose $R$, Weyand $M$, Lammers $M$, Ishizaki $T$, Ahmadian $M R$, Wittinghofer A (2005b) Structural and mechanistic insights into the interaction between Rho and mammalian Dia. Nature 435: 513-518

Rose R, Wittinghofer A, Weyand M (2005a) The purification and crystallization of mDia1 in complex with RhoC. Acta Crystallogr $F$ 61: $225-227$

Scheffzek K, Klebe C, Fritz-Wolf K, Kabsch W, Wittinghofer A (2002) Crystal structure of the nuclear Ras-related protein Ran in its GDP-bound form. Nature 374: 378-381

Shimada A, Nyitrai M, Vetter IR, Kuhlmann D, Bugyi B, Narumiya S, Geeves MA, Wittinghofer A (2004) The core FH2 domain of diaphanous-related formins is an elongated actin binding protein that inhibits polymerization. Mol Cell 13: $511-522$

Vetter IR, Nowak C, Nishimoto T, Kuhlmann J, Wittinghofer A (1999) Structure of a Ran-binding domain complexed with Ran bound to a GTP analogue: implications for nuclear transport. Nature 398: 39-46

Vetter IR, Wittinghofer A (2001) The guanine nucleotide-binding switch in three dimensions. Science 294: 1299-1304

Wallar BJ, Alberts AS (2003) The formins: active scaffolds that remodel the cytoskeleton. Trends Cell Biol 13: 435-446

Watanabe N, Kato T, Fujita A, Ishizaki T, Narumiya S (1999) Cooperation between mDial and ROCK in Rho-induced actin reorganization. Nat Cell Biol 1: 136-143

Watanabe N, Madaule P, Reid T, Ishizaki T, Watanabe G, Kakizuka A, Saito Y, Nakao K, Jockusch BM, Narumiya S (1997) p140mDia, a mammalian homolog of Drosophila diaphanous, is a target protein for Rho small GTPase and is a ligand for profilin. EMBO J 16: $3044-3056$

Wear MA, Yamashita A, Kim K, Maéda Y, Cooper JA (2003) How capping protein binds the barbed end of the actin filament. Curr Biol 13: 1531-1537

Wiseman T, Williston S, Brandts JF, Lin LN (1989) Rapid measurement of binding constants and heats of binding using a new titration calorimeter. Anal Biochem 179: 131-137

Xu Y, Moseley JB, Sagot I, Poy F, Pellman D, Goode BL, Eck MJ (2004) Crystal structures of a formin homology-2 domain reveal a tethered dimer architecture. Cell 116: 711-723

Zigmond SH (2004) Formin-induced nucleation of actin filaments. Curr Opin Cell Biol 16: 99-105

Zigmond SH, Evangelista $\mathrm{M}$, Boone $\mathrm{C}$, Yang $\mathrm{C}$, Dar AC, Sicheri F, Forkey J, Pring M (2003) Formin leaky cap allows elongation in the presence of tight capping proteins. Curr Biol 13: $1820-1823$ 